\title{
Competitividad exportadora de una economía petrolera-gasera: el caso de Trinidad y Tabago, 1985-2010
}

\author{
Indira Romero-Márquez y Juan Carlos Moreno-Brid
}

RESUMEN

El sector del petróleo y el gas (sobre todo a partir del año 2000) ha liderado la economía de Trinidad y Tabago desde finales de los años setenta, gravitando fuertemente en el PIB, las exportaciones totales y los ingresos fiscales. Pero sus perspectivas de mediano plazo pueden deteriorarse si la explotación petrolífera y gasífera aumenta en otros países, y si los Estados Unidos de América alcanzan la autosuficiencia energética. Por ello, resulta relevante analizar la evolución y competitividad de sus exportaciones petroleras y no petroleras, aplicando el indicador de ventaja comparativa revelada, también empleado por la CEPAL tanto en el mercado estadounidense, como a nivel mundial. Se incluyen además otros indicadores de comercio exterior para conocer las características del intercambio comercial de Trinidad y Tabago. Se analiza el período 1985-2010 y los resultados presentados procuran impulsar la diversificación exportadora de este país con miras a mercados más dinámicos y diversificados.

PALABRAS CLAVE

CLASIFICACIÓN JEL

AUTORES
Petróleo, gas natural licuado, exportaciones, competitividad, comercio exterior, política de exportación, diversificación de las exportaciones, estadísticas comerciales, Trinidad y Tabago

F14, N16, N56, O13, O54

Indira Romero-Márquez es Funcionaria de la Sede Subregional de la Comisión Económica para América Latina y el Caribe (CEPAL) en México. indira.romero@cepal.org

Juan Carlos Moreno-Brid es Director Adjunto de la Sede Subregional de la Comisión Económica para América Latina y el Caribe (CEPAL) en México. juancarlos.moreno@cepal.org 


\section{I}

\section{Introducción}

Situada en el sur del mar Caribe, Trinidad y Tabago tiene uno de los mayores niveles de desarrollo entre las islas de la región. Desde finales de la década de 1970, el sector del petróleo y gas ha sido el motor principal de su crecimiento, que actualmente tiene un peso importante en el producto interno bruto (PIB) (alrededor del 40\%), las exportaciones $(75 \%)$ y los ingresos fiscales $(40 \%)$. Hoy en día es el quinto productor de gas natural licuado (GNL) en el mundo. Durante el período comprendido entre 2000 y 2012, su PIB real creció a una tasa media anual de $4,3 \%$, dos puntos por sobre la media latinoamericana. Así, en 2012, su ingreso nacional bruto per cápita de casi 22 mil dólares de paridad del poder adquisitivo duplicó con creces el promedio de toda América Latina y el Caribe. Sin embargo, su dependencia exportadora y fiscal del petróleo y el gas hace que la economía trinitaria sea muy sensible a los vaivenes de precios en el mercado internacional de petrolíferos. Como se expondrá en las siguientes secciones, esta economía no tiene diversificados sus socios comerciales a los que exporta, y tampoco sus productos, y se halla muy especializada en pocos de ellos (la mayoría derivados de recursos no renovables) cuyos precios son volátiles en el mercado internacional ${ }^{1}$. Para una economía pequeña y abierta como la de Trinidad y Tabago, el intercambio comercial es fundamental para su desarrollo ${ }^{2}$, por lo que las características señaladas de su comercio entrañan riesgos que en el futuro cercano pueden tener implicaciones negativas en su desempeño económico y en el bienestar de su población.

Además, el panorama económico del país puede complicarse en el mediano plazo, en la medida que aumente la explotación de petróleo y gas en otros países y se avance hacia la autosuficiencia energética en los Estados Unidos de América, relacionada con el desarrollo de los campos de gas de esquisto (shale gas). Cabe notar que a esta preocupación se añade el bajo nivel relativo de las reservas petrolíferas y de gas de Trinidad y Tabago. El cuociente de reservas sobre

\footnotetext{
1 Trinidad y Tabago goza temporalmente de preferencias arancelarias de los Estados Unidos de América, su principal socio comercial, pero en el futuro cercano estas pueden revertirse, como le sucedió a Jamaica, por ejemplo, lo que repercutió negativamente en su intercambio comercial. 2 Actualmente, el peso en el total de sus exportaciones de bienes y servicios es del 103\%, por debajo del 119\% logrado en 2006.
}

producción de petróleo a fines de 2012 fue de 18,8 , por debajo del promedio mundial $(52,9)$, de la Organización de Países Exportadores de Petróleo (OPEP) (88,5), y de los países petroleros no integrantes de la OPEP $(25,8)$. El cuociente respectivo para el gas natural fue de 8,9 para Trinidad y Tabago, inferior al de los Estados Unidos de América $(12,1)$ y de la Federación de Rusia $(55,6)$. La situación se complica más en el área del gas natural, dado el fuerte incremento reciente de su producción en los Estados Unidos de América y otros países.

Lo expuesto da origen a varias interrogantes. ¿En qué medida Trinidad y Tabago puede seguir teniendo un elevado crecimiento económico cimentado en petróleo y gas?, ¿será necesario comenzar en el mediano o corto plazo la reconversión de su estructura productiva hacia otros sectores? De hecho, como se verá más adelante, la evolución de su comercio revela que cierto cambio estructural quizás ya está en marcha. En efecto, la participación de las exportaciones de petróleo en el total ha ido disminuyendo de manera importante. De este modo, mientras que en 1985 estas representaron el $66 \%$ del total exportado, en el año 2000 su participación se redujo al $46 \%$ y en 2010 era de $39,8 \%$.

Existe abundante literatura sobre los riesgos y potenciales efectos adversos sobre el crecimiento de largo plazo de economías cuyos auges se cimentan en la exportación de ciertos productos básicos (commodities), como es el caso de los recursos minerales. Dichos auges se acompañan de la reasignación de la inversión y otros factores a la producción de commodities, en perjuicio de las manufacturas y de los restantes sectores comerciables. Este fenómeno, conocido como "enfermedad holandesa" en referencia a lo ocurrido en la década de 1970 en los Países Bajos a raíz del auge exportador de petróleo del mar del Norte (Corden y Neary, 1982), es de interés para entender retos cruciales que puede enfrentar la economía de Trinidad y Tabago y de diversos países en América del Sur. Tales procesos, además de la reorientación de factores, inducen una apreciación cambiaria real que repercute negativamente en el crecimiento del resto de los sectores exportadores, en particular de las manufacturas (Aguirre y Calderón, 2005). Sumada a estos retos, la dependencia del ingreso fiscal de la evolución de las exportaciones de commodities introduce una vulnerabilidad adicional, ante la gran volatilidad de los precios en el mercado 
internacional asociada a la baja elasticidad-precio de su oferta en el corto plazo. En Trinidad y Tabago, como en México y otros países, donde un porcentaje importante de los ingresos tributarios proviene de este sector, el gasto del gobierno puede estar sujeto a acentuadas fluctuaciones con impactos adversos en el crecimiento económico (véase, por ejemplo, Loayza y otros, 2007).

Dado lo anterior, el propósito del presente artículo es analizar la evolución de la competitividad de las exportaciones de bienes, petroleros y no petroleros, de Trinidad y Tabago en los últimos 25 años. El marco analítico se apoya en la perspectiva de las ventajas comparativas reveladas (VCR) que introdujera Balassa $(1965,1977,1986)^{3}$. El trabajo se organiza de la siguiente

3 En diversos documentos de la CEPAL (véase pie de página 5), se plantean una serie de conceptos y una metodología de medición de la competitividad con un enfoque comparativo entre países o grupos de países. En este sentido, la competitividad se define como el proceso de integración dinámica de países y productos a mercados internacionales ex post, dependiendo tanto de las condiciones de oferta como de la demanda. A través de las principales herramientas utilizadas en este documento: Análisis de la competitividad de los países (CAN) y Módulo para Analizar el Crecimiento del Comercio Internacional (MAGIC), se examina la competitividad asociada a la capacidad de las exportaciones de un país de incrementar su participación en el mercado internacional; manera. Luego de esta Introducción, en la sección II se muestra la evolución del crecimiento económico, las exportaciones de hidrocarburos y el desempeño comercial no petrolífero, lo que revela la vulnerabilidad de la economía trinitaria a fluctuaciones del mercado del petróleo. Esta vulnerabilidad subraya la relevancia de examinar la competitividad de las exportaciones no petroleras del país. En la sección III se reporta la metodología adoptada y se examinan los diferentes índices al respecto. A continuación, en la sección IV, se analiza la evolución del contenido tecnológico de las exportaciones de Trinidad y Tabago, sus principales socios comerciales y la competitividad de sus diversas actividades. En la sección V se examinan los resultados derivados de la construcción de matrices sobre la base del índice de ventajas comparativas reveladas (IVCR). Las conclusiones del estudio se ofrecen en la sección VI.

es decir, la competitividad se revela en el mercado internacional. En este sentido, un sector gana competitividad si su participación en el comercio internacional se acrecienta y es mayor aún si este aumento se lleva a cabo en sectores en los que la demanda de este tipo de productos es dinámica en el mercado receptor. Más detalles sobre esta metodología se presentan en la sección III.

\section{II}

\section{Trinidad y Tabago: crecimiento económico y comercio internacional}

En 1994, la economía de Trinidad y Tabago logró finalmente salir de la larga recesión que afectó a su desempeño en los años ochenta, y registró un fuerte repunte hacia fines de la década de 1990, impulsada por el alza del precio del petróleo en el mercado internacional. El peso del favorable contexto externo en esta acelerada recuperación, que condujo a su economía a tasas anuales de expansión por sobre el $6 \%$ y $7 \%$, se refleja en un aumento mayúsculo de las exportaciones como proporción del PIB y en el registro de un persistente y notable superávit en la cuenta comercial de la balanza de pagos (véase el gráfico 1). Destaca a la vez en este período la contracción de las importaciones como proporción del producto, asociada a la sustitución de producción local por algunos rubros específicos, muy significativos, en las compras externas del país. Este repunte evidencia desde entonces las características típicas de un auge liderado por las exportaciones, pues la actividad económica mantiene un marcado impulso a la par con el dinamismo de las ventas externas, y este a su vez refleja cercanamente la evolución del precio internacional del petróleo. Así, cuando en 2007 baja la intensidad del ritmo exportador también se desacelera la economía local. La estrecha relación entre las exportaciones y el ritmo de actividad económica parece romperse en 2010-2011, en que la economía se estanca no obstante la recuperación de la trayectoria ascendente de las exportaciones y del precio del petróleo (véase el gráfico 2). Parte de la explicación puede hallarse en el comportamiento de las importaciones que, después de años de contraerse como proporción del PIB, suben su participación en más de diez puntos. 
GRÁFICO

Trinidad y Tabago: crecimiento económico y coeficiente de exportaciones e importaciones, 1985-2011

(En porcentajes del PIB)

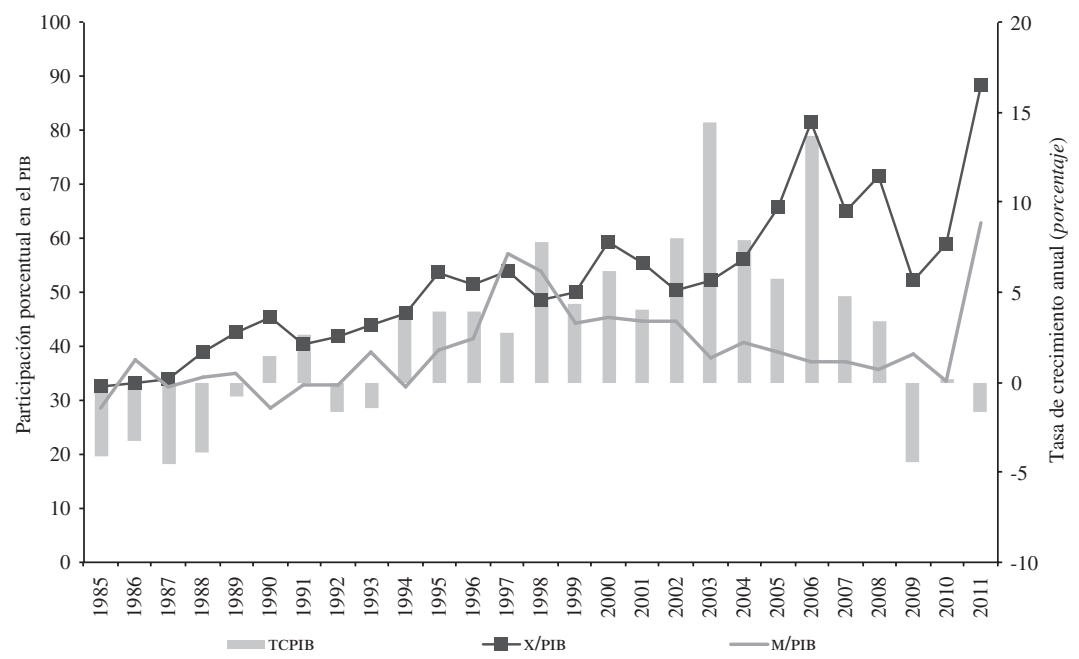

Fuente: Elaboración propia sobre la base de información de la Comisión Económica para América Latina y el Caribe (CEPAL) y el Banco Mundial.

Nota: PIB: Producto interno bruto; TCPIB: Tasa de crecimiento del PIB; XPIB: Tasa de participación de las exportaciones totales en el PIB; M/ PIB: Tasa de participación de las importaciones totales en el PIB.

GRÁFICO 2

Trinidad y Tabago: tasa de crecimiento del PIB, precio del barril de petróleo y balanza comercial no petrolera, 1985-2011

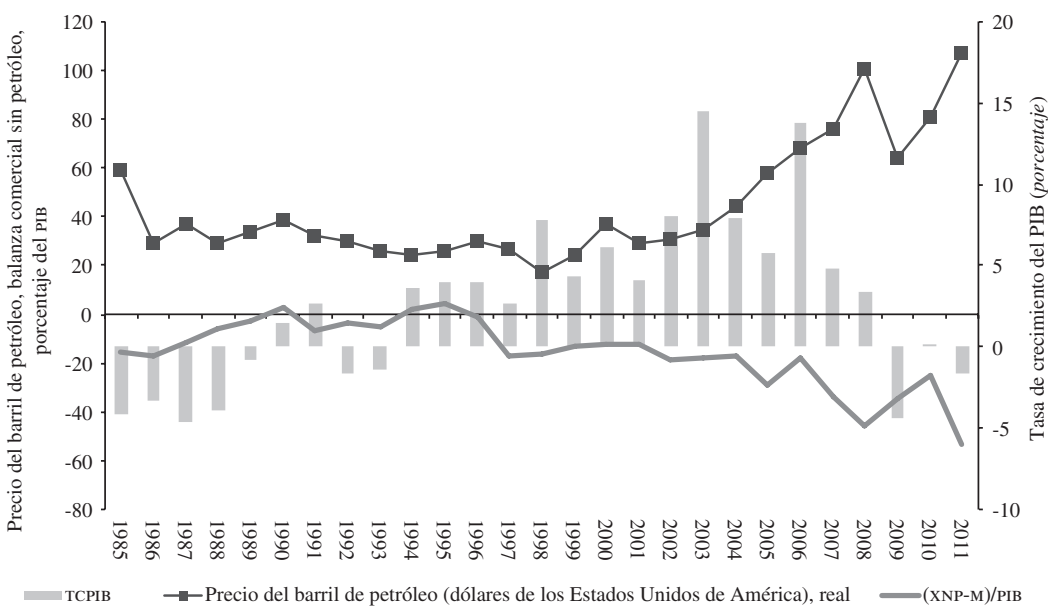

Fuente: Elaboración propia sobre la base de información de la Comisión Económica para América Latina y el Caribe (CEPAL) y el Banco Mundial.

Nota: TCPIB: Tasa de crecimiento del PIB; (XNP-M)/PIB: Exportaciones no petroleras; M: Importaciones; PIB: Producto interno bruto. 
La evolución del comercio exterior de Trinidad y Tabago en estas últimas décadas sugiere, a primera vista, que el crecimiento de su economía no ha estado restringido por el sector externo. En efecto, desde hace dos décadas la expansión de su actividad productiva - en algunos períodos a tasas muy elevadas - se ha visto acompañada de registros superavitarios en la balanza comercial.

El análisis más detenido de dicha balanza apunta en una dirección menos optimista con respecto al peso de la balanza de pagos como restricción al crecimiento de largo plazo, pues su superávit comercial se apoya marcadamente en las ventas de petróleo y gas (véase el gráfico 2). De hecho, si bien la balanza comercial total es superavitaria, su componente no petrolero arroja desde hace tiempo un déficit que se ha ido ensanchando agudamente en los últimos diez años. En 2006 alcanzó un monto equivalente al 18\% del PIB y en 2001 sobrepasó el 50\% del PIB correspondiente (véase el gráfico 2). Este deterioro de la balanza comercial no petrolera puede ser motivo de preocupación, ya que ilustra la alta dependencia de esta economía de los recursos petroleros para cerrar su balance comercial y preservar el ritmo de expansión económica. En la medida en que los precios del petróleo están sujetos a elevada volatilidad de corto plazo y quizás a tendencias a la baja en el largo plazo debido a la presión de la oferta de variados combustibles, gas de esquisto, entre otros. Ello subraya la necesidad, si no la urgencia, que tiene Trinidad y Tabago de diversificar su canasta exportadora, como respuesta preventiva a un shock externo adverso en el mercado petrolero internacional.

\section{III}

\section{Metodologías para el estudio del desempeño exportador ${ }^{4}$}

\section{El índice de la ventaja comparativa revelada (IVCR)}

Este indicador se construye sobre la base de información de flujos de comercio internacional para determinar el grado de competitividad que tiene un producto de un país en específico. Balassa (1965) se refirió al concepto de IVCR para señalar que las ventajas comparativas

\footnotetext{
${ }^{4} \mathrm{Si}$ bien en la mayor parte de los análisis incluidos en este documento se utiliza la herramienta CAN, también ellos se apoyan en algún momento en el software del World Integrated Trade Solution (WITS), desarrollado por el Banco Mundial en colaboración con la Conferencia de las Naciones Unidas sobre Comercio y Desarrollo (UNCTAD) y en consulta con varias organizaciones internacionales como el Centro de Comercio Internacional, la División de Estadística de las Naciones Unidas y la Organización Mundial del Comercio (OMC). Entre los indicadores incluidos en el wits y que se utilizan en este análisis se encuentran: la participación del país en las exportaciones mundiales; la participación del producto en las exportaciones mundiales; el índice de concentración Hirschmann Herfindahl (una medida de diversificación de productos); el IVCR, y el índice de penetración en el mercado de exportación, entre otros. La explicación detallada de estos indicadores y otros más se puede encontrar en el manual del programa, que se puede descargar de la siguiente página web: http:// wits.worldbank.org/wits.
}

entre países pueden ser "reveladas" a través del flujo de comercio de bienes; los que, en última instancia, reflejan las diferencias en costos y precios relativos y otros elementos que inciden en las ventajas comparativas entre los distintos países, las que pueden ir más allá de factores de mercado ${ }^{5}$.

El IVCR compara la participación de las exportaciones de un producto en el total exportado por un país con la participación de las exportaciones de dicho producto en el mercado mundial, o en un mercado regional o nacional específico de referencia. Se construye de la siguiente manera:

$$
I V C R_{i}^{j}=\frac{x_{i}^{j} / x_{i}^{o}}{X_{o}^{j} / X_{o}^{o}} \equiv \frac{x_{i}^{j} / X_{o}^{j}}{x_{i}^{o} / X_{o}^{o}}
$$

\footnotetext{
5 Para una descripción detallada de la metodología, véanse Hernández y Romero (2009). Para estudios empíricos sobre la base de su aplicación, véase la serie de estudios de la Comisión Económica para América Latina y el Caribe (CEPAL), entre otros: Buitelaar (1997); Mortimore, Buitelaar y Bonifaz (2000); Dussel (2001 y 2004); Martínez y Cortés (2004), y Hernández, Romero y Cordero (2006).
} 
donde: $x_{i}^{j}$ son las exportaciones del sector o producto $i$ provenientes del país $j ; x_{i}^{o}$ son las exportaciones del producto $i$ del mercado de referencia; $X_{o}^{j}$ es el total de exportaciones del país $j ; X_{o}^{o}$ es el total de exportaciones del mercado de referencia. Todos los valores están expresados en dólares corrientes. El denominador del IVCR representa la participación de las exportaciones de un sector o producto en las exportaciones del mercado de referencia. El IVCR muestra para un producto (o grupo de productos) la comparación entre la estructura de exportaciones de un país (el numerador) y la estructura de exportaciones de un mercado de referencia (el denominador). Cuando el IVCR es igual a la unidad (1) para un producto (o grupo de productos) de un país en particular, la proporción de exportaciones totales del país que es aportada por dicho producto (o grupo de productos) es idéntica a la del mercado de referencia. Cuando respecto de un producto (o grupo de productos) el IVCR es superior a la unidad, se concluye que el país en cuestión en su comercio exportador está especializado en dicho producto en comparación con el mercado de referencia. Cuando el IVCR es menor que 1 , la conclusión es la inversa, es decir, que el país carece de ventaja comparativa revelada en el comercio en dicho producto.

\section{El enfoque del análisis de competitividad de las naciones (CAN)}

Con el objetivo de profundizar en el análisis del desempeño de las diferentes economías y subregiones en el comercio internacional, la CEPAL ha extendido la utilización del IVCR en una metodología denominada CAN (por sus siglas en inglés). Con esta, se construye una serie de indicadores que extienden el IVCR a partir de la información de la Base de Datos Estadísticos de las Naciones Unidas sobre el Comercio de Productos Básicos (COMTRade). En su versión más reciente, COMTRADE registra información de series de tiempo para el período 1985-2010 de una muestra de 73 países, de los cuales 23 son industrializados y el resto en vías de desarrollo. Actualmente, los registros de exportaciones e importaciones cubren el $90 \%$ del comercio mundial y están expresados en dólares corrientes de los Estados Unidos de América.

Según la metodología del CAN, los datos de COMTRADE se procesan de varias formas. Por una parte, se calculan agregados regionales de las importaciones para dos grandes grupos de economías: i) de países industrializados y ii) de países en desarrollo. A la vez, la información de comercio se desagrega en diversas subregiones para cada una de estas dos agrupaciones. En el conjunto de países industrializados se distinguen tres grupos: i) América del Norte; ii) Europa occidental; y iii) otros industrializados. En el de países en desarrollo se identifican: i) África; ii) Asia y iii) América ${ }^{6}$. Los datos de importaciones se listan en más de 230 grupos de productos de acuerdo con la Clasificación Uniforme para el Comercio Internacional (CUCI) revisión 2, es decir, a nivel de agregación de tres dígitos. Posteriormente se calculan promedios móviles de tres años de la información de comercio proveniente de COMTRADE, con excepción del dato del año más reciente (actualmente 2011) para el que se promedió su valor con el del año previo.

Por medio de estadística descriptiva, el CAN amplía la línea metodológica basada en las ventajas comparativas reveladas (VCR) y posibilita el análisis de la evolución de la estructura sectorial de las exportaciones de un producto o grupos de productos de un país, de sus participaciones de mercado y del dinamismo de su demanda internacional. A partir de estos indicadores se elabora un conjunto de matrices que proporcionan indicadores sintéticos de la situación competitiva de las exportaciones de un país en un período y un mercado externo de referencia dado. La posición competitiva de un país queda establecida por la evolución de la participación de sus exportaciones en un mercado externo determinado dado en un período seleccionado. A su vez, toma en cuenta el dinamismo de la demanda de los distintos productos que exporta.

El CAN representa un avance importante con respecto al IVCR para describir y evaluar la situación competitiva y comparativa internacional de los distintos países en un período relativamente largo, por sectores o productos específicos. Pero, al igual que el IVCR, es tan solo un enfoque descriptivo de la competitividad exportadora de una economía determinada. No constituye un modelo explicativo de los factores subyacentes de la competitividad detectada, no distingue si la competitividad lograda es sostenible a largo plazo, ni identifica la evolución de los costos de producción, transporte o de otro tipo. En ese mismo terreno, al abordar las cifras en precios corrientes, el CAN omite del análisis la separación de los fenómenos de precio y de volumen. Finalmente, en tanto se basa en datos de ventas a precios corrientes, la metodología del CAN no ofrece información sobre la evolución y el

\footnotetext{
${ }^{6}$ Este grupo de países se desagrega en cuatro divisiones: i) Comunidad Andina de Naciones; ii) Comunidad del Caribe (CARICOM); iii) Central American Common Market (CACM); (iv) Mercado Común del Sur (MERCosur), y v) otros países en desarrollo de América.
} 
significado del valor agregado local o extranjero de los diferentes productos exportados. Por esto último, las medidas de competitividad que se registran en el CAN consideran indistintamente a economías cuyas estructuras productivas están muy integradas y aportan un valor agregado significativo al comercio de aquellas cuyos procesos productivos son en gran medida de ensamblaje (maquila, con mínimo valor agregado).

\section{IV}

\section{El comercio internacional de Trinidad y Tabago: su desempeño en el período 1985-2010 ${ }^{7}$}

Por tratarse de una economía pequeña, la participación de Trinidad y Tabago en las exportaciones totales mundiales ha sido sistemáticamente muy baja, si bien - como se aprecia en el gráfico 3- ha tenido fluctuaciones importantes. Su participación de 0,13\% en 1985 se redujo en los años siguientes y llegó en 1995 a $0,05 \%$. Aunque tuvo una recuperación parcial en años posteriores, la crisis financiera global de 2008-2009 la afectó y su participación se contrajo para quedar en 2010 prácticamente en la mitad de su registro 25 años atrás.

\footnotetext{
${ }^{7}$ El período de análisis de este documento es el comprendido entre 1985 y 2010. Cabe señalar que, en general, en esta sección se presentan algunas estadísticas indicando que el período de análisis corresponde a 1985-2010, por lo que se entiende que no solo se incluyen los años 1985 y 2010, sino también años intermedios: 1990, 1995, 2000 y 2005. En varios de los análisis se especifica el período de esta manera: 1985/2010 o bien 2010/1985; cuando esto ocurre, quiere decir que solo están incluidos el año inicial (o sea: 1985 o el promedio móvil 1984-1986
}

El destino principal de las exportaciones de Trinidad y Tabago a lo largo del período de análisis ha sido de manera preponderante los Estados Unidos de América, aunque ha logrado cierta diversificación. En efecto, mientras que en 1985 el $62 \%$ de sus exportaciones se dirigían al mercado estadounidense, en 2010 esta cifra fue de $48 \%$. Países caribeños como Barbados, Jamaica y Suriname figuran entre sus socios, así como algunos países europeos y centroamericanos. En todo caso, la participación individual de estos mercados es aún reducida (véase el gráfico 4 ).

GRÁFICO 3

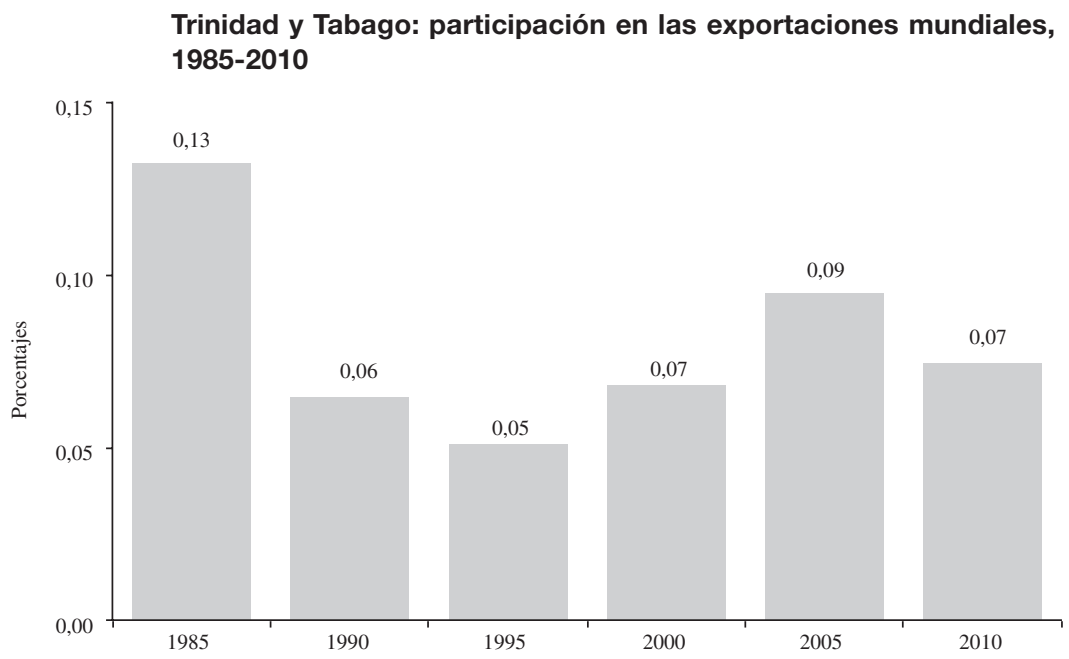

Fuente: Elaboración propia sobre la base de información de World Integrated Solution (WITs). 
GRÁFICO 4

Trinidad y Tabago: principales socios comerciales, 1985, 2000 y 2010

1985 2000
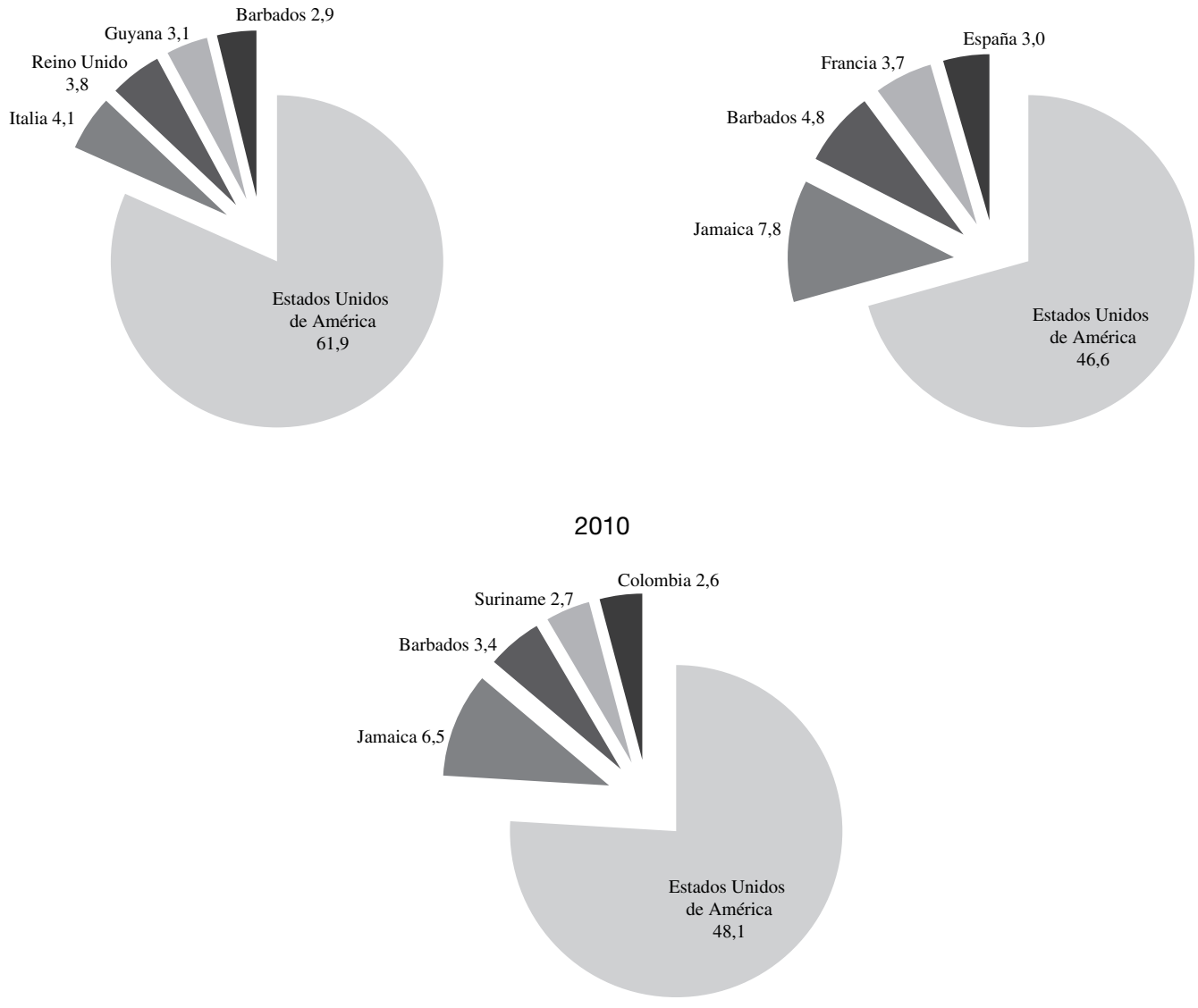

Fuente: Elaboración propia sobre la base de información de World Integrated Solution (WITs).

Trinidad y Tabago es una economía petrolera y, también, un productor muy importante de gas natural licuado, lo que se refleja en la composición de sus productos exportados. En efecto, sus principales exportaciones durante el período 1985-2010 provinieron del sector del gas y el petróleo y estuvieron muy concentradas en pocos productos. De esta manera, en 1985 el petróleo, sus productos derivados y conexos 8 representaron el 78,8\% del total exportado; el resto de las exportaciones consistió en productos químicos orgánicos e inorgánicos, fertilizantes manufacturados, así como hierro y acero. La participación de este sector ha decaído

8 Capítulo 33 de la Clasificación Uniforme para el Comercio Internacional (CUCI) a lo largo del período, con algunas fluctuaciones debido a los vaivenes en el precio internacional del petróleo. Si bien en 2010 el petróleo seguía siendo el principal producto exportado, su peso en el total de exportaciones había bajado al 43,7\%. Llama la atención que en 2000 las exportaciones de gas natural y manufacturado ${ }^{9}$ alcanzaron una participación del $13 \%$ en el mercado estadounidense y de 9,2\% en el mercado mundial, mientras que en 1985 sus participaciones correspondientes eran de virtualmente cero en el caso de los Estados Unidos de América y de $0,7 \%$ en el mercado mundial. Otros de los productos con preponderancia en las exportaciones de Trinidad y

\footnotetext{
9 Capítulo 34 de la Clasificación Uniforme para el Comercio Internacional (CUCI).
} 
Tabago en 2010 fueron menas ${ }^{10}$ y desechos de metales ${ }^{11}$. Para entonces, los principales productos exportados del país fueron el petróleo, sus derivados y conexos (43,7\%); el gas natural y manufacturado $(17,2 \%)$; los productos químicos inorgánicos $(13,4 \%)$; los productos químicos orgánicos $(5,8 \%)$; así como las menas y desechos de metales $(5,2 \%)$. Estos cinco productos aportaron el $85 \%$ del total exportado.

En el cuadro 1 se presenta la composición de las exportaciones de Trinidad y Tabago tanto al mercado mundial como al de los Estados Unidos de América (su principal socio comercial), clasificadas en función de su contenido tecnológico.

Durante el período de estudio, las exportaciones destinadas al resto del mundo se concentran en las mismas dos categorías, pero con distinto peso: productos primarios (PP) y manufacturas basadas en recursos naturales (RBM), con más del $80 \%$ del total exportado. Las manufacturas de tecnología media (MTM) han ganado participación de

${ }^{10}$ El término "mena" hace referencia a un mineral del que se puede extraer un elemento, un metal generalmente, por contenerlo en cantidad suficiente para ser aprovechado. Un mineral es mena de un metal cuando mediante minería es posible extraer ese mineral de un yacimiento y luego mediante metalurgia obtener el metal de ese mineral.

11 Capítulo 28 de la CUCI. manera sostenida dentro del total, en tanto que las de baja tecnología presentan fluctuaciones con tendencia a la baja, sobre todo a partir de 2005. Las exportaciones dirigidas al mercado de los Estados Unidos de América se concentran también (y aún más) en PP y RBM, si bien la importancia de las primeras ha declinado más rápido y la de las manufacturas basadas en recursos naturales se ha incrementado. Por otra parte, las manufacturas de tecnología media (MTM) han crecido en importancia desde el año 2000 y la participación de las LTM y нтм es casi despreciable (véase el cuadro 1).

Como era de esperar, siendo Trinidad y Tabago una economía petrolera, pequeña y sumamente abierta, la composición de sus importaciones por contenido tecnológico es más diversa que la de sus exportaciones. En efecto, las compras de мтм tienen la mayor participación en las importaciones en los años noventa, pero esta desciende casi diez puntos hacia 2010. Las importaciones de PP crecen en importancia hasta ser el rubro mayoritario y alcanzar el $52,9 \%$ en $2010^{12}$

\footnotetext{
12 La creciente participación de los productos primarios en las importaciones totales provenientes del resto del mundo se debe a las mayores cantidades importadas de petróleo crudo para su refinación en Trinidad y Tabago y posterior reexportación.
}

CUADRO 1

Trinidad y Tabago: exportaciones al mundo y a los Estados Unidos de América,
1985-2010
(En porcentajes con respecto al total)

Trinidad y Tabago: exportaciones al resto del mundo

\begin{tabular}{|c|c|c|c|c|c|c|}
\hline & \\
\hline & 1985 & 1990 & 1995 & 2000 & 2005 & 2010 \\
\hline PP & 2,33 & 3,66 & 8,30 & 12,9 & 14,36 & 26,79 \\
\hline RBM & 79,75 & 63,82 & 66,26 & 63,93 & 66,75 & 52,56 \\
\hline LTM & 3,11 & 16,2 & 8,54 & 9,59 & 6,5 & 4,54 \\
\hline MTM & 11,9 & 12,4 & 14,16 & 12,65 & 10,88 & 15,67 \\
\hline НTM & 2,4 & 3,08 & 2,44 & 0,39 & 1,02 & 0,21 \\
\hline OT & 0,51 & 0,84 & 0,30 & 0,54 & 0,5 & 0,23 \\
\hline
\end{tabular}

Trinidad y Tabago: exportaciones a los Estados Unidos de América

\begin{tabular}{|c|c|c|c|c|c|c|}
\hline & 1985 & 1990 & 1995 & 2000 & 2005 & 2010 \\
\hline $\mathrm{PP}$ & 74,85 & 64,58 & 45,37 & 43,99 & 58,79 & 38,57 \\
\hline RBM & 18,93 & 29,39 & 47,69 & 40,97 & 26,15 & 51,07 \\
\hline LTM & 1,31 & 1,65 & 1,25 & 4,29 & 1,07 & 0,56 \\
\hline MTM & 4,28 & 4,23 & 4,65 & 10,81 & 13,85 & 9,82 \\
\hline HTM & 0,52 & 0,07 & 1,03 & 0,29 & 0,13 & 0,00 \\
\hline OT & 0,12 & 0,09 & 0,02 & 0,05 & 0,01 & 0,00 \\
\hline
\end{tabular}

Fuente: Elaboración propia sobre la base de información de World Integrated Solution (WITS).

Nota: PP: Productos primarios; RBM: Manufacturas basadas en recursos naturales; LTM: Manufacturas de baja tecnología; мтм: Manufacturas de tecnología media; нтм: Manufacturas de alta tecnología; ot: Otros productos.

a Son cuatro partidas del código CUCI (Clasificación Uniforme para el Comercio Internacional) las que se incluyen en esta categoría: 333, 341, 334 y 335; las dos primeras se incluyen en el grupo de PP y las dos últimas en el de RBM. 
(véase el cuadro 2). Las importaciones provenientes de los Estados Unidos de América se concentran en MTM y su participación aumenta a lo largo del período. Destaca también la participación en el total tanto de las RBM como de las HTM, observándose una (relativa) mayor estabilidad en la participación de las RBM durante el período de estudio. Finalmente, la reducción de la participación de los PP es notable sobre todo a partir del año 2000, disminución a la que contribuyeron, principalmente, las menores importaciones de semillas y frutos oleaginosos y de arroz ${ }^{13}$.

\section{Ventaja comparativa revelada (VCR)}

Sobre la base del IVCR los datos a nivel de dos dígitos de las exportaciones de Trinidad y Tabago revelan que en 1985 solo cuatro sectores (de un total de 67) tenían

\footnotetext{
${ }^{13}$ La participación de las importaciones de semillas y frutos oleaginosos disminuyó drásticamente. En 1990 su peso dentro del total importado era de $27,1 \%$, de $23,8 \%$ en 1995; sin embargo, en 2000 cayó a casi $4 \%$, aunque se recuperó en el siguiente quinquenio (12,3\%). Finalmente, en 2010 su peso en el total importado por Trinidad y Tabago registró un nivel muy similar al de comienzos de esa década.
}

una ventaja comparativa manifestada (VCR): productos químicos orgánicos (52), petróleo, productos derivados y conexos (33), fertilizantes manufacturados (56), así como azúcares, preparados de azúcar y miel (06). Entre 1990 y 1995, el número de sectores con VCR superior a la unidad se elevó a entre 9 y 11 , aunque todavía pocos con respecto al total (véase el gráfico 5). De esta manera, en 1990 se agregaron a dicho grupo varios sectores más: hierro y acero (67), bebidas (11), productos y preparados comestibles diversos (09), pienso para animales (excepto cereales sin moler), así como abonos en bruto y materiales en bruto (excepto carbón) (27). En tanto que en 1995, 11 sectores tenían una VCR (véase el gráfico 3), y entre los nuevos sectores se encuentran el gas natural y manufacturado (34), productos químicos orgánicos (51) y aceites esenciales y resinoides y productos de perfumería, preparados de tocador y para pulir y limpiar (55).

En el año 2000, este subgrupo se redujo a nueve sectores, pues tanto el sector de pienso para animales (08) como el de los aceites esenciales y resinoides (55) dejaron de presentar una VCR. En el año 2005, los sectores con la mayor VCR resultaron ser los productos químicos inorgánicos (52) y el gas natural y manufacturado (34). Los otros sectores con un índice superior a 1 son los mismos del año 2000, únicamente se anexó el tabaco

CUADRO 2

Trinidad y Tabago: importaciones provenientes del mundo y de los Estados Unidos de América, 1985-2010

(En porcentajes con respecto al total)

\begin{tabular}{|c|c|c|c|c|c|c|}
\hline & \multicolumn{6}{|c|}{ Trinidad y Tabago: importaciones provenientes del resto del mundo } \\
\hline & 1985 & 1990 & 1995 & 2000 & 2005 & 2010 \\
\hline $\mathrm{PP}$ & 21,25 & 34,36 & 21,80 & 54,79 & 50,95 & 52,85 \\
\hline RBM & 21,49 & 18,98 & 14,07 & 11,86 & 14,87 & 11,75 \\
\hline LTM & 16,60 & 13,15 & 14,81 & 7,64 & 7,88 & 8,19 \\
\hline MTM & 29,89 & 23,59 & 39,59 & 20,47 & 20,66 & 20,79 \\
\hline HTM & 9,35 & 8,42 & 7,48 & 4,61 & 4,95 & 6,01 \\
\hline OT & 1,20 & 1,51 & 2,25 & 0,63 & 0,69 & 0,41 \\
\hline \multirow[t]{3}{*}{ Petróleo y gas ${ }^{\mathrm{a}}$} & 5,1 & 18,7 & ND & 49,6 & 48,2 & 44,4 \\
\hline & \multicolumn{6}{|c|}{ Trinidad y Tabago: importaciones provenientes de los Estados Unidos de Améric } \\
\hline & 1985 & 1990 & 1995 & 2000 & 2005 & 2010 \\
\hline $\mathrm{PP}$ & 16,14 & 21,31 & 16,24 & 5,15 & 8,53 & 10,38 \\
\hline RBM & 16,75 & 15,71 & 8,20 & 12,97 & 14,44 & 17,22 \\
\hline LTM & 14,05 & 9,89 & 11,15 & 10,32 & 11,54 & 11,85 \\
\hline MTM & 38,84 & 37,42 & 47,99 & 37,78 & 48,91 & 42,33 \\
\hline HTM & 11,82 & 14,56 & 15,28 & 32,74 & 15,51 & 17,34 \\
\hline OT & 2,40 & 1,11 & 1,14 & 1,03 & 1,07 & 0,88 \\
\hline Petróleo y gas ${ }^{\mathrm{a}}$ & 0,4 & 0,6 & 0,4 & 0,7 & 2,3 & 4,5 \\
\hline
\end{tabular}

Fuente: Elaboración propia sobre la base de información de World Integrated Solution (WITs).

Nota: PP: Productos primarios; RBM: Manufacturas basadas en recursos naturales; LTM: Manufacturas de baja tecnología; мтм: Manufacturas de tecnología media; нтм: Manufacturas de alta tecnología; от: Otros productos.

a Son cuatro partidas del código CUCI (Clasificación Uniforme para el Comercio Internacional) las que se incluyen en esta categoría: 333 , 341,334 y 335; las dos primeras se incluyen en el grupo de PP y las dos últimas en el de RBM. 
y sus productos (12). En el año 2010, los productos químicos inorgánicos y el gas natural permanecieron como los sectores con la mayor VCR, y aparecieron sectores como las menas y desechos de metales (28) y, sorpresivamente, otro equipo de transporte (79). Cabe señalar que en 2010 , los productos químicos inorgánicos resultaron ser, por mucho, el sector con el mayor índice de VCR (véase el gráfico 3).

Es evidente que durante el período de análisis (1985-2010), en la economía de Trinidad y Tabago fue ampliándose y diversificándose el número de sectores con VCR. Sin embargo, con excepción de gas, químicos orgánicos e inorgánicos, hierro y acero, el peso en el total exportado de los nuevos sectores competitivos es bastante reducido. En el gráfico 5 se registra el peso relativo de los sectores en las exportaciones totales del país a través del tamaño de las "burbujas". Se evidencia claramente que en los distintos quinquenios, la mayor parte de los nuevos sectores con VCR tienen un bajo peso relativo en las exportaciones de Trinidad y Tabago al mundo. En los hechos, el petróleo y el gas, a partir del año 2000, continúan siendo sectores competitivos preponderantes en las exportaciones del país, aunque el primero haya perdido gravitación en el total.

GRÁFICO 5

Trinidad y Tabago: sectores con ventaja comparativa revelada (VCR) superior a la unidad, 1985-2010

(IVCR y número de sectores)

Trinidad y Tabago: vCR, 1985
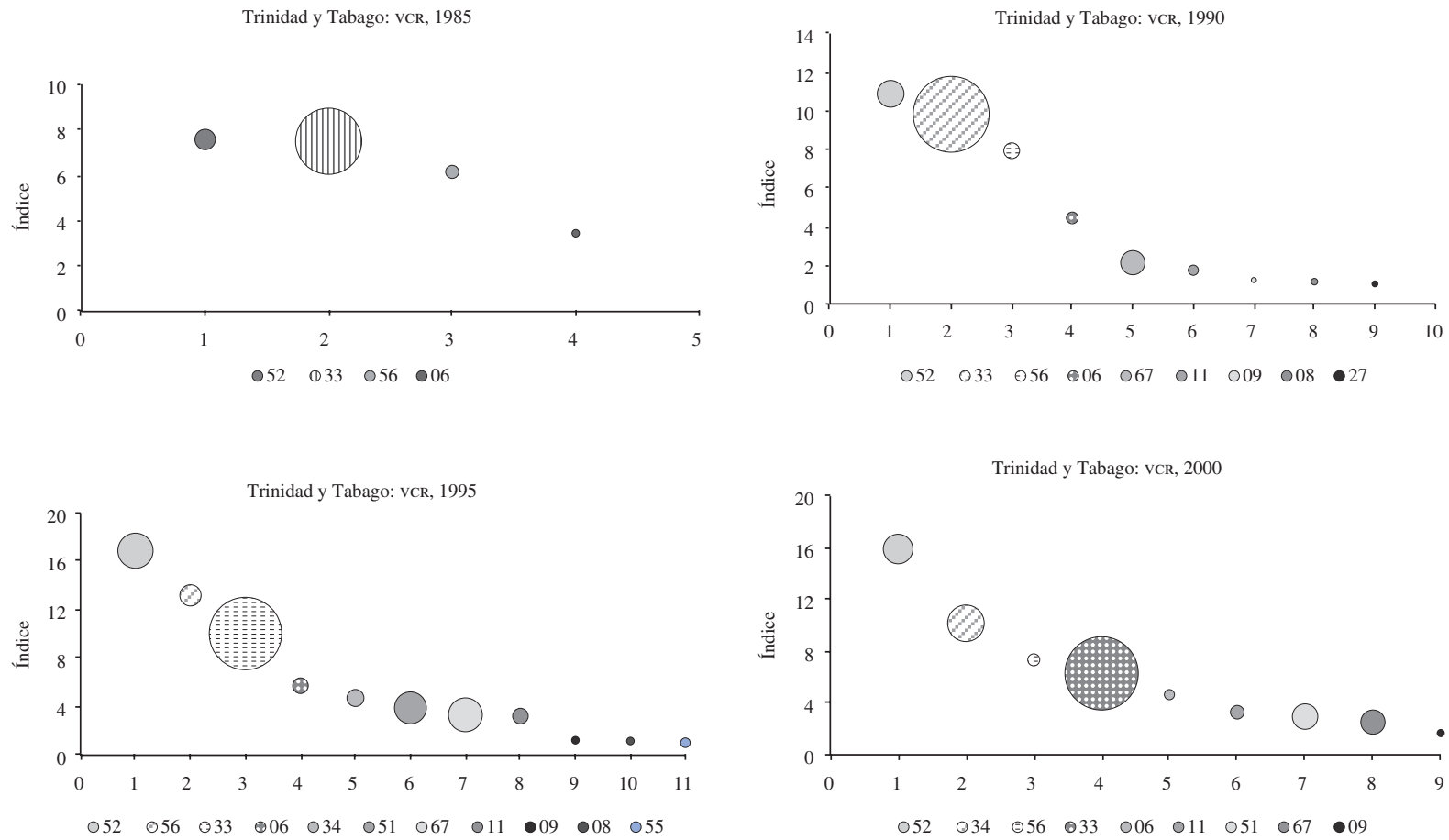

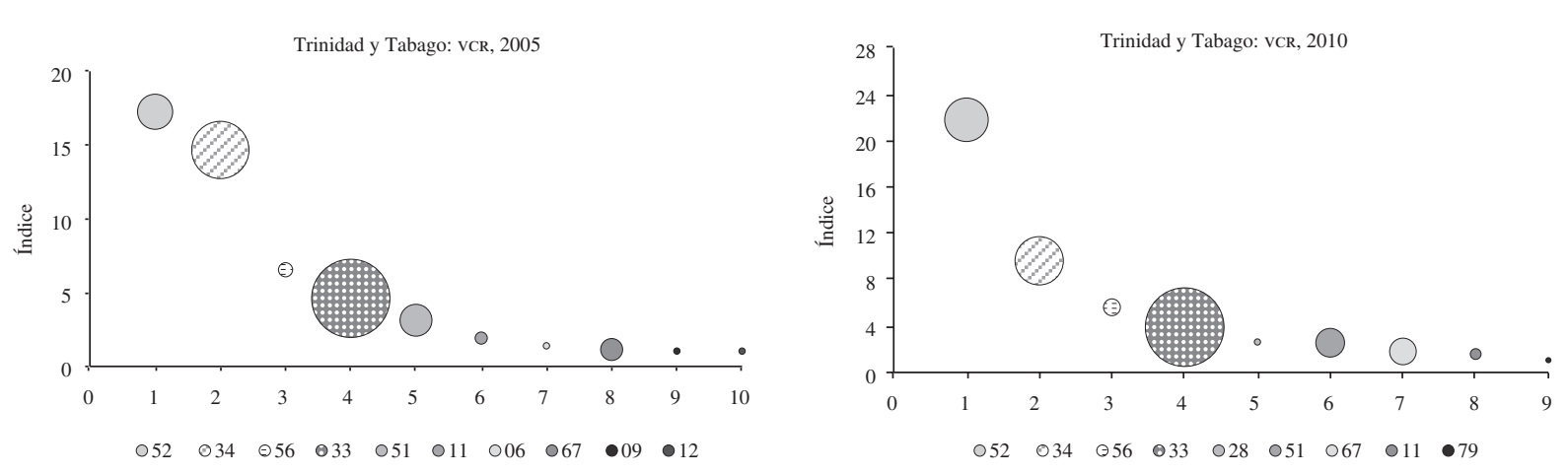

Fuente: Elaboración propia sobre la base de información de World Integrated Solution (wITs).

Nota: El tamaño de las burbujas refleja el peso relativo de las exportaciones de cada sector en el total de exportaciones de Trinidad y Tabago. Los dígitos en el eje horizontal junto a los círculos corresponden a la Clasificación Uniforme para el Comercio Internacional (CUCI). IVCR: Índice de ventaja comparativa revelada.

\section{Medición complementaria de la VCR: el índice de Lafay (ILF)}

Lafay (1979) creó un indicador en cierto sentido más integral para medir el grado en que un país tiene, en un producto o sector determinado, una ventaja comparativa en el comercio internacional. A diferencia del IVCR utilizado en la subsección anterior, el ILF incorpora en su construcción información sobre las importaciones y la balanza comercial, y no solo sobre las exportaciones. Dicho indicador pertenece a la familia de índices de especialización y se define así:

$$
I L F_{i}^{j}=100\left[\frac{X_{i}^{j}-M_{i}^{j}}{X_{i}^{j}+M_{i}^{j}}-\frac{\sum_{i=1}^{n} X_{i}^{j}-M_{i}^{j}}{\sum_{i=1}^{n} X_{i}^{j}+M_{i}^{j}}\right] \frac{X_{i}^{j}+M_{i}^{j}}{\sum_{i=1}^{n} X_{i}^{j}+M_{i}^{j}}
$$

donde $X_{i}^{j}$ y $M_{i}^{j}$ son las exportaciones e importaciones de un producto o sector $i$ del país $j$ al resto del mundo y desde el resto de mundo, respectivamente, y $n$ es el número de grupos o productos comercializados. Como su construcción señala, el índice, la ventaja comparativa del país $j$ en la exportación del bien $i$ se mide por la desviación de la balanza comercial normalizada de dicho bien en el comercio total respecto de la balanza comercial total normalizada. Luego, este resultado se multiplica por la participación comercial (exportaciones más importaciones) del bien $i$ en el comercio total.
Valores positivos del índice de Lafay se toman como indicador de la existencia de ventajas comparativas en dicho producto o bien $i$. Valores negativos del índice indican la ausencia de ventajas comparativas.

El ILF indica que Trinidad y Tabago centra sus exportaciones en un número relativamente reducido de sectores, lo que confirma los resultados previos. A lo largo de todo el período de análisis, sus sectores, en este sentido exitosos en el comercio internacional, se restringen a tres grandes agregados: alimentos bebidas y tabaco, recursos naturales, hierro y acero, y químicos. De un total de 67 sectores, en 1985 solo seis tienen un ILF positivo: i) azúcares, preparados de azúcar y miel (06); ii) café, té, cacao, especias y sus preparados (07); iii) petróleo, productos derivados y productos conexos (33); iv) productos químicos orgánicos (51); v) productos químicos inorgánicos (52), y vi) fertilizantes manufacturados (56). En 1990, prácticamente permanecen los mismos sectores y se agrega el de las bebidas (11). Tanto en 1995 como en 2000 se amplía el número de sectores en que se concentra el país caribeño (véase el cuadro 3) al anexarse: pescado (no incluidos los mamíferos marinos); crustáceos, moluscos e invertebrados acuáticos y sus preparados (03); menas y desechos de metales (28); productos animales y vegetales en bruto (29); gas natural y manufacturado (34), y hierro y acero (67). En 2005 y 2010 se reduce nuevamente el número de sectores exportadores a seis: menas y desechos de metales (28); petróleo sus derivados y productos conexos (33); gas natural y manufacturado (34); productos químicos orgánicos (51); productos químicos inorgánicos (52), y fertilizantes manufacturados (56). 
Trinidad y Tabago: sectores con ventaja competitiva en el comercio internacional, 1985-2010

(Según índice de Lafay (ILF))

\begin{tabular}{lccc}
\hline & & \multicolumn{2}{c}{ Sector con ventaja comparativa } \\
\cline { 2 - 4 } Año & Alimentos y bebidas & $\begin{array}{c}\text { Recursos naturales } \\
\text { y hierro/acero }\end{array}$ & $\begin{array}{c}\text { Químicos orgánicos } \\
\text { e inorgánicos/abonos } \\
\text { Otros }\end{array}$ \\
\hline 1985 & 06,07 & 33 & $51,52,56$ \\
1990 & $06,07,11$ & 33 & $51,52,56$ \\
1995 & $03,06,07,11$ & $28,33,34,67$ & $51,52,56$ \\
2000 & $03,06,11$ & $28,33,34,67$ & $51,52,56$ \\
2005 & ---- & $28,33,34$ & $51,52,56$ \\
2010 & ---- & $28,33,34$ & $51,52,56$ \\
\hline
\end{tabular}

Fuente: Elaboración propia sobre la base de información de World Integrated Solution (WITs).

Nota: La descripción de los códigos de los sectores según la Clasificación Uniforme para el Comercio Internacional (cuci) se encuentra en el anexo, cuadro A.3.

---- : productos sin ventajas comparativas.

\section{3. Índice de concentración/diversificación Hirschmann-Herfindahl (IHH)}

Para completar el análisis del desempeño exportador del país, la información sobre las ventajas comparativas obtenida mediante los índices de Lafay y de Balassa se complementó con un indicador de su concentración medida por el índice IHH que se calcula de la siguiente forma:

$$
I H H=\left(\frac{\sum_{j=1}^{n} p_{h}^{2}-\frac{1}{n}}{1-\frac{1}{n}}\right)
$$

donde $p_{h}=X_{h j} / X T_{h}$ indica la participación del país $j$ en las exportaciones del país $h$ en el total de sus exportaciones al mundo $X T_{h}$. A la suma de los cuadrados de todas las participaciones se le conoce como Índice de Herfindahl. Como en este caso se corrige por el número de observaciones, se adoptó la metodología de Hirschmann-Herfindahl, que permite comparar resultados entre diversos productos o sectores, países de destino de exportaciones o ambos, al presentarlos de manera normalizada. De este modo, un país con un portafolio de exportaciones perfectamente diversificado tendrá un índice cercano a 0 , en tanto que un país que solo exporta un producto tendrá un valor de 1 .
El IHH para las exportaciones de Trinidad y Tabago tiene un valor elevado, sobre todo en 1985, lo que ratifica el relativamente bajo número de sectores que concentran el grueso de las exportaciones. Como se describió, en el período bajo estudio si bien siguieron predominando los sectores de petróleo y gas, se ha generado cierta diversificación de exportaciones, lo que se refleja en un valor del Інн de alrededor de 0,25-0,30, menos de la mitad de su registro en 1985 (véase el gráfico 6).

A manera de conclusión de esta sección, aunque el país ha logrado cierta diversificación de sus exportaciones, el petróleo y gas y los químicos orgánicos e inorgánicos todavía concentran la mayor parte de las ventas al exterior. De la misma manera, durante el período el número de socios comerciales se ha incrementado, aunque los Estados Unidos de América continúan siendo el principal socio comercial de Trinidad y Tabago en cuanto a las exportaciones. Por otra parte, si bien subió, siguió siendo muy limitado el número de sectores con VCR. En efecto, en 1985 solo cuatro sectores tenían VCR y en 1995 su número se había duplicado con creces (11). Sin embargo, en 2010 eran solo nueve los sectores con un índice de VCR superior a la unidad, y nuevamente los sectores con mayor peso en el total exportado seguían siendo los de petróleo y derivados, gas y productos químicos inorgánicos. 
GRÁFICO 6

Trinidad y Tabago: Índice Hirschmann-Herfindahl (IHH), 1985-2010

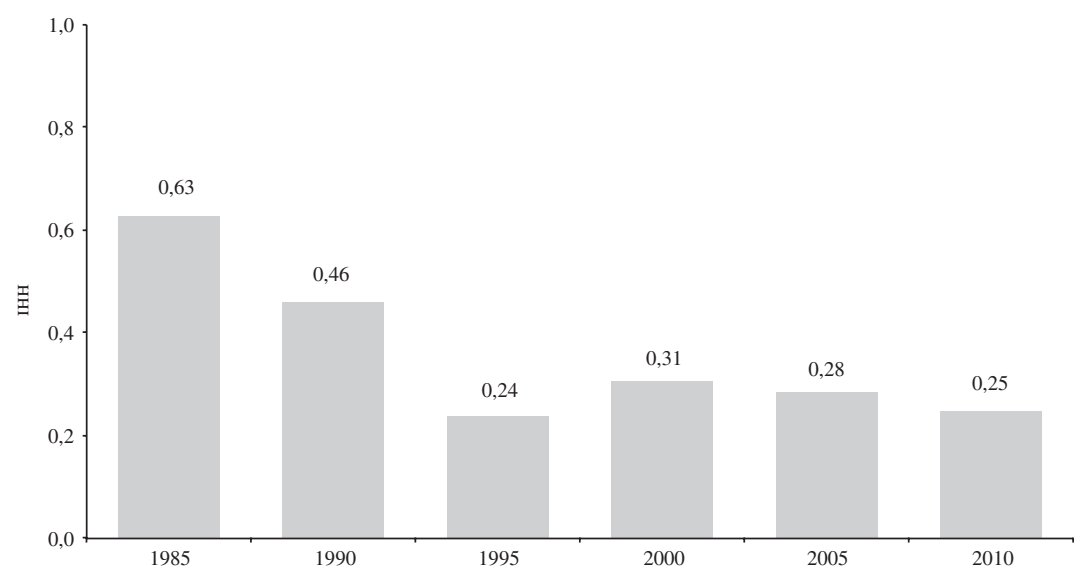

Fuente: Elaboración propia sobre la base de información de World Integrated Solution (wITs).

\section{V}

\section{Matrices de competitividad. Análisis por capítulos y por contenido tecnológico}

En esta sección se examinan los resultados derivados de la construcción de matrices que sobre la base del índice de VCR reflejan la competitividad exportadora de los diferentes sectores de Trinidad y Tabago, tomando en cuenta su inserción en los nichos dinámicos — o estáticosdel mercado mundial o de mercados seleccionados relevantes, por ejemplo, el estadounidense. La matriz de competitividad está conformada por un cuadrante de doble entrada en el que los ejes representan información, por una parte, de la evolución de las exportaciones del país y, por otra, del dinamismo de sus mercados de destino, es decir, del dinamismo de las importaciones en el mercado mundial o en mercados seleccionados. Así, el eje horizontal captura la variación de las importaciones mundiales e indica si esta es dinámica o rezagada. A su vez, el eje vertical mostrará la capacidad de un país de adaptar la estructura de sus exportaciones a las condiciones del mercado internacional ${ }^{14}$ (véase el gráfico 7 ).

\footnotetext{
${ }^{14}$ En el caso de CAN, en el eje vertical se incluye una de las siguientes tres variables: participación de mercado; porcentaje de exportaciones, y especialización. Para el propósito de este documento, únicamente se incluye la participación de mercado.
}

A partir de esta matriz surgen cuatro categorías o cuadrantes en que se clasifica un producto de acuerdo con la evolución de sus exportaciones a un mercado seleccionado y con la evolución relativa de la demanda internacional de dicho producto, en un período dado.

- Estrellas nacientes: concierne a productos cuya participación en el total de importaciones aumenta en el período, y a la vez las exportaciones de dicho producto por el país —en este caso Trinidad y Tabago - ganan participación en dicho mercado, es decir, crece su participación en el mercado de referencia.

- $\quad$ Estrellas menguantes: categoría compuesta por los productos cuyo peso en las importaciones totales en el mercado de referencia se reduce, pero que aumentan su participación de mercado.

- Oportunidades perdidas: aquellos productos que incrementan su porcentaje de participación en las importaciones totales, pero en los que la variación en la participación de mercado es negativa, es decir, se reduce.

- $\quad$ Retirada: se refiere a las situaciones en que tanto la variación correspondiente en el porcentaje de importaciones como de participación de mercado es negativa. 


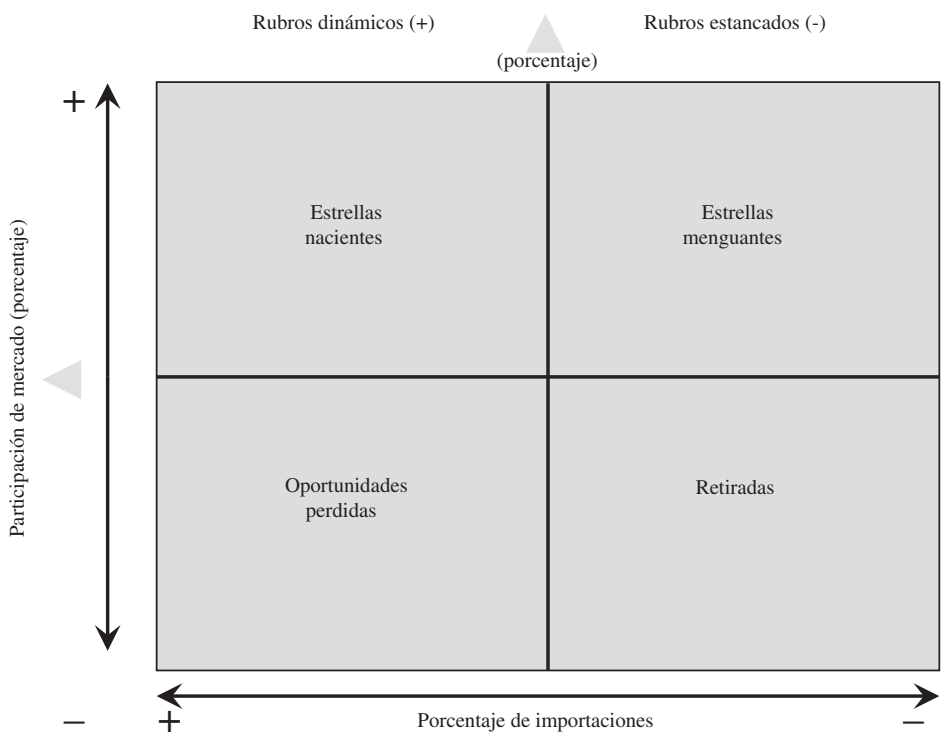

Fuente: Elaboración propia.

Sobre la base de esta metodología, en el análisis de las exportaciones de Trinidad y Tabago se procedió de dos maneras. En principio, se obtuvo la tipología de producto por contenido tecnológico y se agregó la categoría de exportaciones no petroleras. Además, la tipología de producto se obtuvo para dos mercados importadores: el mundo ${ }^{15}$ y los Estados Unidos de América con respecto a dos subperíodos (1985-2000 y 2000-2010) y para todo el período (1985-2010). En segundo lugar, se obtuvo la misma tipología (o matriz de competitividad) para los mismos mercados importadores, pero para todos los sectores incluidos en la Clasificación Uniforme para el Comercio Internacional (CUCI), esto es, para un total de 67 sectores (también llamados capítulos) y para los mismos tres períodos.

Los resultados (véase el cuadro 4) indican que en el mercado mundial, los productos no petroleros - cuando se comparan los años 2010 y 1985- caen en la categoría de "oportunidades perdidas", esto es, al mismo tiempo que las importaciones de este producto en el mercado mundial crecieron, la participación de Trinidad y Tabago en este mercado se contrajo en dicho período. Si se divide el lapso de análisis en dos partes, y se comparan los años 2000 y 1985, entonces las exportaciones

\footnotetext{
15 No incluye a los Estados Unidos de América.
}

CUADRO 4

\section{Trinidad y Tabago: composición de sus exportaciones}

(Por contenido tecnológico e inserción competitiva en el mercado mundial, excluidos los Estados Unidos de América)

\begin{tabular}{|c|c|c|c|}
\hline & $2000 / 1985$ & $2010 / 2000$ & $2010 / 1985$ \\
\hline $\mathrm{PP}$ & EM & EN & EM \\
\hline RBM & $\mathrm{RE}$ & $\mathrm{OP}$ & $\mathrm{RE}$ \\
\hline LTM & EN & $\mathrm{RE}$ & $\mathrm{RE}$ \\
\hline MTM & EN & $\mathrm{RE}$ & EN \\
\hline HTM & OP & $\mathrm{RE}$ & OP \\
\hline OT & OP & мо & $\mathrm{OP}$ \\
\hline No petroleros & EN & RE & $\mathrm{OP}$ \\
\hline
\end{tabular}

Fuente: Elaboración propia sobre la base del programa CAN.

Nota: PP: Productos primarios; RBM: Manufacturas basadas en recursos naturales; LTM: Manufacturas de baja tecnología; мтм: Manufacturas de tecnología media; HTM: Manufacturas de alta tecnología; от: Otros productos; Ем: Estrellas menguantes; RE: Retiradas; EN: Estrellas nacientes; OP: Oportunidades perdidas.

no petroleras al mundo se ubican en la categoría de "estrellas nacientes", es decir, sus importaciones a nivel mundial aumentaron, al igual que su participación de mercado. Entre 1985 y 2010, los principales productos de exportación de Trinidad y Tabago, PP y RBM, no tuvieron 
una evolución favorable en el mercado internacional. Los productos primarios (PP) se comportaron como "estrellas menguantes" (su participación de mercado se acrecienta, pero las importaciones mundiales de este producto no lo hacen, y las manufacturas basadas en recursos naturales (RBM) se comportaron como "retiradas", pues sus importaciones mundiales disminuyeron y también lo hizo su participación de mercado.

Por otra parte, en el mercado de los Estados Unidos de América las exportaciones no petroleras fueron una "estrella naciente" en el primer lapso (2000/1985). En el segundo cayeron en la categoría de "estrella menguante", de manera que para el período en su conjunto (19852010) también quedaron así clasificadas. Los sectores con mayor participación en las exportaciones totales (PP y RBM) tuvieron un comportamiento diferenciado en dos subperíodos (2000/1985 y 2010/2000) y el período en su conjunto (1985-2010). Mientras que los PP cayeron en la categoría de "oportunidades pérdidas" tanto en 2000-2010 como en 1985-2010 (véase el cuadro 5), en el lapso 1985-2000 se catalogaron como "retiradas", es decir, tanto su participación de mercado como su participación en el total importado por el mercado estadounidense disminuyó. Por otra parte, las RBM cayeron en la categoría de "estrellas menguantes" tanto en 1985-2000 como en el lapso 1985-2010. En el lapso intermedio (2010/2000) tanto su participación de mercado como su participación en las importaciones totales de los Estados Unidos de América aumentó, clasificándose por lo tanto como "estrellas nacientes" (véase el cuadro 5).

CUADRO 5

Trinidad y Tabago: tipología de sectores

(Mercado importador: Estados Unidos de América)

\begin{tabular}{l|ccc}
\hline & $2000 / 1985$ & $2010 / 2000$ & $2010 / 1985$ \\
\hline PP & RE & OP & OP \\
RBM & EM & EN & EM \\
LTM & EN & RE & RE \\
MTM & EM & EM & EM \\
HTM & EN & EM & EN \\
OT & OP & EM & OP \\
No petroleros & EN & EM & EM \\
\hline
\end{tabular}

Fuente: Elaboración propia sobre la base del programa CAN.

Notaa: PP: Productos primarios; RBM: Manufacturas basadas en recursos naturales; LTM: Manufacturas de baja tecnología; MTM: Manufacturas de tecnología media; нтм: Manufacturas de alta tecnología; от: Otros productos; EM: Estrellas menguantes; RE: Retiradas; EN: Estrellas nacientes; OP: Oportunidades perdidas.
La tipología por contenido tecnológico de las exportaciones ofrece una primera aproximación para comprender las diferentes dinámicas de inserción de las actividades productivas de Trinidad y Tabago en el comercio internacional, pero su nivel de agregación no permite identificar en más detalle los sectores que fueron exitosos y los que no durante el período estudiado. Esta identificación es particularmente relevante para un país que, si bien concentra sus exportaciones en pocos productos, ha hecho esfuerzos por diversificar su canasta exportadora.

\section{Competitividad internacional: resultados por principales productos de exportación (a dos dígitos de la Cucl)}

Como se ha visto repetidamente, los principales productos de exportación de Trinidad y Tabago durante 1985-2010 han sido el petróleo, productos derivados y productos conexos; gas natural y manufacturado; productos químicos orgánicos; productos químicos inorgánicos y hierro y acero $^{16}$ (este último especialmente importante en el mercado mundial). El comportamiento de estos productos en términos de la matriz de competitividad ha variado según el subperíodo y mercado de destino (los Estados Unidos de América o el resto del mundo). De esta manera, en el mercado estadounidense el petróleo en el primer período (2000/1985) se ubicó en la categoría de "retirada", esto es, tanto la variación de su participación de mercado como de la estructura de importaciones fue negativa. En el mercado mundial, se clasificó como "estrella menguante", es decir, mientras aumentó su participación de mercado, en la estructura de importaciones de los Estados Unidos de América su peso disminuyó. En el siguiente período (2010/2000), en ambos mercados las exportaciones de petróleo se clasificaron como "estrellas menguantes". Cuando se toman los años 1985 y 2010, la situación de este grupo de productos no cambia (véase el cuadro A.1 del anexo) en el mercado estadounidense, pero en el mercado mundial se ubica en la categoría de "retiradas". En este sentido, la situación competitiva del petróleo fue relativamente mejor en el mercado estadounidense que en el mundial.

La evolución competitiva de las exportaciones de gas natural y manufacturado en ambos mercados tendió a ser mejor que la del petróleo. Fue "estrella naciente" en 2000/1985 en el mercado estadounidense y en el mercado mundial en 2010/2000; en el resto de los períodos es una "estrella menguante" en ambos mercados.

\footnotetext{
${ }^{16}$ Corresponden a los numerales 33, 34, 51, 52 y 67 de la Clasificación Uniforme para el Comercio Internacional (CUCI).
} 
La situación competitiva de las exportaciones de productos químicos orgánicos hacia los Estados Unidos de América fue la ideal, pues a lo largo de todo el período de análisis se ubicó como "estrella naciente". En el mercado mundial la situación competitiva fue similar, excepto que en el período 2010/2000 la variación de la demanda fue negativa (y la de la oferta positiva), por lo que se colocó en la categoría de "estrella menguante" (véase el cuadro A.2 del anexo).

Los productos químicos inorgánicos enfrentaron en general una situación competitiva adversa en el mercado mundial, solo en el subperíodo intermedio (2010/2000) se ubicaron en la categoría de "estrella naciente", y en el subperíodo 2000/1985 y el período completo (2010/1985) este grupo de productos fue catalogado como "retirada". En el mercado estadounidense enfrentaron una situación favorable ("estrella naciente") en el subperíodo intermedio (2010/2000), pero en los otros dos períodos (2000/1985 y 2010/1985) fueron "estrellas menguantes", es decir, mientras que aumentó su participación de mercado, en la estructura de importaciones de los Estados Unidos de América su peso disminuyó (véase el cuadro A.1 del anexo).

Finalmente, el hierro y el acero tuvieron un desempeño competitivo no tan favorecedor en el mercado mundial. En efecto, tanto en el superíodo (2000/1985) como en el período completo 2010/1985, este grupo se ubicó en la categoría de "estrella menguante". En el subperíodo intermedio (2010/2000) su situación se deterioró hasta clasificarse como "oportunidad perdida" (véase el cuadro A.2 del anexo). En el mercado estadounidense su desempeño no fue mejor; en el primer período (2000/1985) fue "estrella menguante", pasó a la situación opuesta en el período 2010/2000 (“oportunidad perdida"), con lo que para todo el período 2010/1985 en su conjunto representó una "retirada".

\section{Resultados consolidados}

Teniendo como mercado importador a los Estados Unidos de América, los resultados para el primer período (2000/1985) dejan ver que aquellos productos con un crecimiento muy dinámico de su participación en la estructura importadora se enfrentaron a dos escenarios. Así, los productos considerados "estrellas nacientes" en el período 1985/2000 aumentaron considerablemente su participación en el total de exportaciones al pasar de representar un 2,2\% en 1985 al $24,5 \%$ en 2000 , en tanto que aquellos productos bajo la categoría de "oportunidades perdidas" incrementaron levemente su participación en el total exportado (véase el cuadro 6).

Por otra parte, los productos ubicados en la categoría de "estrellas menguantes" representaron el 74,6\% de las exportaciones totales de Trinidad y Tabago en 1985, y aumentaron al $77 \%$ en 2000 , si bien su participación en el mercado estadounidense es relativamente baja (véase el cuadro 6). Los productos en la categoría de "retiradas" tuvieron un alto peso en las exportaciones de Trinidad y Tabago en 1985; sin embargo, lo redujeron

CUADRO 6

Resultados consolidados para Trinidad y Tabago

(Mercado importador en porcentajes: Estados Unidos de América)

\begin{tabular}{|c|c|c|c|c|}
\hline & & $1985 / 2000$ & $2000 / 2010$ & $1985 / 2010$ \\
\hline \multirow{3}{*}{ Estrellas nacientes } & Participación de mercado & $0,6 / 2,8$ & $5,7 / 7,0$ & $1,2 / 1,9$ \\
\hline & Estructura exportadora de Trinidad y Tabago & $2,2 / 24,5$ & $25,1 / 23,2$ & $2,2 / 7,1$ \\
\hline & Estructura importadora de los Estados Unidos de América & $24,4 / 34,0$ & $3,5 / 5,9$ & $3,4 / 6,3$ \\
\hline \multirow{3}{*}{ Estrellas menguantes } & Participación de mercado & $3,6 / 7,9$ & $1,7 / 7,2$ & $2,6 / 13,8$ \\
\hline & Estructura exportadora de Trinidad y Tabago & $10,5 / 27,1$ & $12,8 / 29,4$ & $7,5 / 48,0$ \\
\hline & Estructura importadora de los Estados Unidos de América & $19,3 / 14,5$ & $1,5 / 1,4$ & $8,1 / 6,0$ \\
\hline \multirow{3}{*}{ Oportunidades perdidas } & Participación de mercado & $0,2 / 0,1$ & $4,1 / 2,3$ & $2,3 / 0,8$ \\
\hline & Estructura exportadora de Trinidad y Tabago & $0,6 / 1,1$ & $56,5 / 47,2$ & $85,8 / 44,4$ \\
\hline & Estructura importadora de los Estados Unidos de América & $13,2 / 18,5$ & $26,9 / 39,0$ & $39,1 / 51,5$ \\
\hline \multirow{3}{*}{ Retiradas } & Participación de mercado & $2,7 / 1,2$ & $0,5 / 0,1$ & $1,0 / 0,1$ \\
\hline & Estructura exportadora de Trinidad y Tabago & $86,7 / 47,4$ & $5,6 / 0,2$ & $4,4 / 0,5$ \\
\hline & Estructura importadora de los Estados Unidos de América & $35,0 / 25,2$ & $59,4 / 45,3$ & $41,3 / 26,8$ \\
\hline
\end{tabular}

Fuente: Elaboración propia sobre la base del programa CAN.

Nota: La participación de mercado se obtiene al hacer la división entre el grupo respectivo de productos exportado a los Estados Unidos de América y el total de importaciones del mismo grupo que se registró en los Estados Unidos de América proveniente de todos los países. La estructura exportadora se calcula como la participación del valor de las exportaciones del grupo de productos a los Estados Unidos de América entre el total de productos exportados por Trinidad y Tabago a tal mercado. Es decir, la suma de la estructura exportadora de los diferentes grupos de productos debe ser igual a 100\%. La estructura importadora se obtiene como el cociente del valor de las importaciones de un grupo de productos por los Estados Unidos de América entre el total de productos importados por ese país. 
considerablemente en el año 2000. En la siguiente década (2000/2010), los casos de productos cuyo peso aumentó en las importaciones de los Estados Unidos de América, se enfrentaron a un menor peso dentro de las exportaciones totales de Trinidad y Tabago, aunque la participación porcentual de estos mismos productos fue relevante en ambos casos. La disminución de su importancia en las importaciones de los Estados Unidos de América se enfrentó en un caso (retiradas) a un menor peso de estos productos en el total exportado por Trinidad y Tabago (pasó de 5,6\% a 0,2\%), y en el otro ("estrellas menguantes") a un incremento considerable de su relevancia en el total exportado.

En todo el período (1985-2010), las principales exportaciones de Trinidad y Tabago se ubicaron o bien en "oportunidades pérdidas" o en "estrellas menguantes" (véase el cuadro 6). Si bien es cierto que la participación en el total de exportaciones de aquellos productos ubicados en la categoría de "oportunidades perdidas" se redujo en más de la mitad (del 85,8 al 44,4\%), su peso fue el segundo más considerable. En cuanto a los productos clasificados en la categoría de "estrellas menguantes", su participación en el total exportado por Trinidad y Tabago se incrementó notablemente (del 7,5 al 48\%). Por su parte, subió el peso en el total de las exportaciones de los productos considerados "estrellas nacientes", pero su participación de mercado también es reducida $(1,9 \%)$. En la categoría de "retiradas" se ubica un porcentaje muy bajo de las exportaciones de Trinidad y Tabago a los Estados Unidos de América y también tienen escasa participación de mercado (véase el cuadro 6).

La situación competitiva de los productos exportados por Trinidad y Tabago es relativamente mejor en el mercado estadounidense que en el resto del mercado mundial en conjunto, aunque tampoco es especialmente buena. Con el propósito de efectuar la comparación siguiente conviene concentrarse en la evolución de las exportaciones entre los años 1985 y 2010, si bien su desempeño no fue necesariamente el mismo dentro de los dos subperíodos aquí considerados (1985/2000 y 2000/2010). En primer término, y como es lógico dado el tamaño diferente de los dos mercados de destino, tanto en la categoría de "estrellas nacientes" como en la de "estrellas menguantes", las exportaciones de Trinidad y Tabago ampliaron su penetración en el mercado estadounidense en más puntos porcentuales que en el mercado del resto del mundo. En efecto, en este lapso (1985/2010) las "estrellas nacientes" elevaron su presencia en el mercado estadounidense en casi un punto porcentual $(0,7 \%)$ y en el resto del mundo en apenas una décima de punto $(0,1 \%)$. A su vez, las "estrellas menguantes" acrecentaron su participación en dichos mercados en 10,5 puntos y $0,8 \%$, respectivamente. En segundo término, en 2010 el grupo de "estrellas nacientes" aportó el 7,1\% del total de exportaciones a los Estados Unidos de América y solo el 6,6\% si se toma como referencia el total exportado al resto del mercado mundial. Más contrastante es el desempeño del grupo de las "retiradas" cuya participación en las exportaciones al mercado estadounidense fue de $0,5 \%$, porcentaje que sube al $46 \%$ en el caso de las exportaciones al mercado mundial a finales del período (2010) (véase el cuadro 7). Por otra parte, en el rubro de "oportunidades perdidas" la diferencia es otra vez muy marcada, aunque ahora con cifras más elevadas en el mercado estadounidense (44\%) que en el resto del mundo (2,5\%). Finalmente, el grupo de "estrellas menguantes" registró participaciones similares en la estructura exportadora, ligeramente por debajo del $49 \%$.

CUADRO 7

Resultados consolidados para Trinidad y Tabago

(Mercado importador: mundo sin los Estados Unidos de América)

\begin{tabular}{llccc}
\hline & & & & \\
& & $1985 / 2000$ & $2000 / 2010$ & $1985 / 2010$ \\
\hline \multirow{3}{*}{ Estrellas nacientes } & Participación de mercado & $0,4 / 0,8$ & $0,7 / 1,0$ & $0,1 / 0,2$ \\
& Estructura exportadora de Trinidad y Tabago & $6,5 / 17,5$ & $12,4 / 36,2$ & $2,5 / 6,6$ \\
& Estructura importadora del mundo & $28,3 / 34,9$ & $3,5 / 5,9$ & $7,3 / 9,1$ \\
\hline \multirow{3}{*}{ Estrellas menguantes } & Participación de mercado & $0,5 / 1,5$ & $0,1 / 0,1$ & $0,3 / 1,1$ \\
& Estructura exportadora de Trinidad y Tabago & $74,6 / 76,6$ & $0,7 / 1,0$ & $7,1 / 44,9$ \\
& Estructura importadora del mundo & $45,7 / 30,4$ & $9,3 / 7,6$ & $17,3 / 13,1$ \\
\hline \multirow{4}{*}{ Oportunidades perdidas } & Participación de mercado & $0,1 / 0,0$ & $1,4 / 0,6$ & $0,2 / 0,1$ \\
& Estructura exportadora de Trinidad y Tabago & $1,6 / 1,0$ & $72,7 / 57,2$ & $4,8 / 2,5$ \\
& Estructura importadora del mundo & $14,0 / 27,8$ & $41,6 / 49,7$ & $33,2 / 49,2$ \\
\hline \multirow{5}{*}{ Retiradas } & Participación de mercado & $1,5 / 0,6$ & $0,9 / 0,3$ & $1,9 / 0,7$ \\
& Estructura exportadora de Trinidad y Tabago & $17,3 / 4,8$ & $14,2 / 5,7$ & $85,5 / 46,0$ \\
& Estructura importadora del mundo & $7,1 / 5,3$ & $45,4 / 36,2$ & $38,4 / 28,1$ \\
\hline
\end{tabular}

Fuente: Elaboración propia sobre la base del programa CAN. 


\section{VI}

\section{Conclusiones}

En el presente artículo se muestra cómo la trayectoria de crecimiento de la economía de Trinidad y Tabago y el desempeño de su balanza comercial en las décadas recientes han estado estrechamente ligados a la evolución de las exportaciones de hidrocarburos, si bien las exportaciones de petróleo se han reducido en el total, las exportaciones de gas en buena parte han cubierto esa disminución. Este proceso se ha visto acompañado de un creciente déficit comercial en los sectores no petroleros, que revela una importante vulnerabilidad de la pauta de desarrollo que ha seguido el país, y el peso potencialmente muy relevante que tiene el sector externo como restricción al crecimiento de largo plazo de la economía. En este contexto, cobra importancia que el país diversifique su canasta exportadora más allá de los productos ligados a los hidrocarburos. Los resultados obtenidos en el presente trabajo, siguiendo diferentes metodologías, indican que el país ya ha comenzado desde hace tiempo una diversificación - moderada y todavía con mucho por recorrer- de sus exportaciones. En cuanto a sus mercados de destino, mientras que en 1985 el $62 \%$ de sus exportaciones se dirigía al mercado estadounidense, en 2010 solo se dirigió el 48\%. A su vez, al comienzo del período de análisis (1985), las exportaciones de Trinidad y Tabago denotaban una intensa concentración en productos petroleros y gas natural, que fue diluyéndose en el caso del mercado estadounidense. En 1985, tales productos representaban el $86,5 \%$ del total exportado por Trinidad y Tabago a dicho país, y en 2010 el 62,3\%. En contraste, las exportaciones de Trinidad y Tabago al resto del mundo mostraron una pauta inversa en este aspecto. Las de petróleo y gas natural representaron en 1985 el $67,2 \%$ del total exportado, proporción que en 2010 era ligeramente mayor $(69,4 \%)$. Durante el período examinado (1985-2010), el país fue ampliando y diversificando el número de sectores con VCR, más allá del petróleo. Sin embargo, con excepción de contados sectores (químicos orgánicos e inorgánicos, hierro y acero), el peso en el total exportado de los nuevos sectores competitivos es bastante reducido. De hecho, el petróleo y el gas (a partir del año 2000) continúan siendo los sectores competitivos preponderantes en las exportaciones del país, aunque hayan perdido peso relativo.

El análisis de la matriz de competitividad arrojó que las exportaciones de productos no petroleros - tanto hacia el mercado estadounidense como al del resto del mundo- solo en el período 1985/2000 lograron un buen desempeño, donde se clasificaron en la categoría de "estrellas nacientes". En el mercado de los Estados Unidos de América se ubicaron más bien en la categoría de "estrellas menguantes" en los otros dos períodos considerados (2000/2010 y 1985/2010), es decir, acrecentaron su participación en mercados que perdían peso en el total importado por los Estados Unidos de América. En el mercado mundial, las exportaciones de productos no petroleros se ubican como "retiradas" en 2000/2010 y como "oportunidades perdidas" en 1985/2010. Vale decir que su desempeño competitivo en el mercado estadounidense fue relativamente mejor que en el resto del mundo.

El análisis realizado en este trabajo señala que la situación competitiva de los productos exportados no petroleros es relativamente mejor en el mercado estadounidense que en el del resto del mundo, aunque tampoco es especialmente buena. En el mercado de los Estados Unidos de América, en el subperíodo 1985/2000, la mayor parte de los productos exportados se ubicó en la categoría de "retiradas" — su participación de mercado disminuyó y también lo hizo su participación en el total importado por los Estados Unidos de América-. En el siguiente decenio (2000/2010) la situación cambió de manera apreciable, pues la mayoría clasificó como "oportunidades perdidas" y muy pocos como "retiradas". Los productos catalogados como "estrellas nacientes" -que es una situación ideal en términos de la matriz de competitividad - aumentaron de manera considerable su participación si se comparan los subperíodos 1985/2000 y 2000/2010. De esta manera, los resultados del análisis por medio de la matriz de competitividad indican que el segundo subperíodo fue mejor que el primero.

Durante el primer subperíodo, en el mercado del resto del mundo la mayor parte de las exportaciones de Trinidad y Tabago se concentraron en la categoría de "estrellas menguantes". En el siguiente subperíodo su posición competitiva se deterioró y en su mayoría se ubicaron en "oportunidades pérdidas", esto es, perdieron presencia en mercados dinámicos.

En el mejor comportamiento relativo de las exportaciones en el mercado estadounidense se debe considerar que Trinidad y Tabago cuenta con un acceso preferencial a ese país bajo la Ley de Recuperación Económica de la Cuenca del Caribe, la que requiere de 
autorizaciones por parte de la Organización Mundial del Comercio para ser renovada periódicamente. En mayo de 2009 se procedió a la renovación que termina en $2014^{17}$, es decir, en el futuro cercano es posible que este acceso preferencial termine y que las exportaciones de Trinidad y Tabago tengan que competir con las de muchos otros países bajo las mismas condiciones, lo que genera una mayor presión a objeto de que este país se diversifique tanto en productos, servicios o ambos como en mercados de destino.

Si bien los resultados indican que ha habido avances en la diversificación de la canasta exportadora del país, estos son todavía limitados. Las exportaciones siguen mayoritariamente dominadas por los productos ligados a los hidrocarburos, y son muy pocos los que han cobrado cierta presencia. Más aún, su desempeño competitivo en los Estados Unidos de América y en el del resto del mundo dista de ser exitoso, en la medida en que son muy contados los sectores cuyas exportaciones ganan

\footnotetext{
${ }^{17}$ Continúa vigente el acuerdo con los Estados Unidos de América.
}

presencia en los nichos dinámicos de esos mercados. La dependencia del petróleo y el gas por parte de Trinidad y Tabago es un reto que el país habrá de resolver para reducir su vulnerabilidad a los vaivenes en el precio internacional del petróleo, y enfrentar la amenaza vinculada al surgimiento de nuevos competidores en el mercado mundial, además de la reducción de las preferenciales arancelarias de parte de los Estados Unidos de América. Ello reviste particular importancia, dado que su balanza comercial sin exportaciones petroleras muestra un deterioro considerable en los últimos años. Es de esperar que el análisis empírico aquí realizado y las conclusiones derivadas sean un insumo importante para impulsar la estrategia de diversificación de la canasta exportadora del país, y orientarla a mercados dinámicos, las llamadas "estrellas nacientes". En este sentido, los lineamientos de política contenidos en el documento de la CEPAL (2012) Cambio estructural para la igualdad: una visión integral de desarrollo, resultan particularmente útiles para ayudar a delinear una estrategia holística con miras a un desarrollo económico sostenible, y un sector exportador fuerte, diversificado y competitivo que apoye y complemente al mercado doméstico. 
ANEXO

CUADRO A.1

Trinidad y Tabago: tipología de las exportaciones en el mercado de los Estados Unidos de América

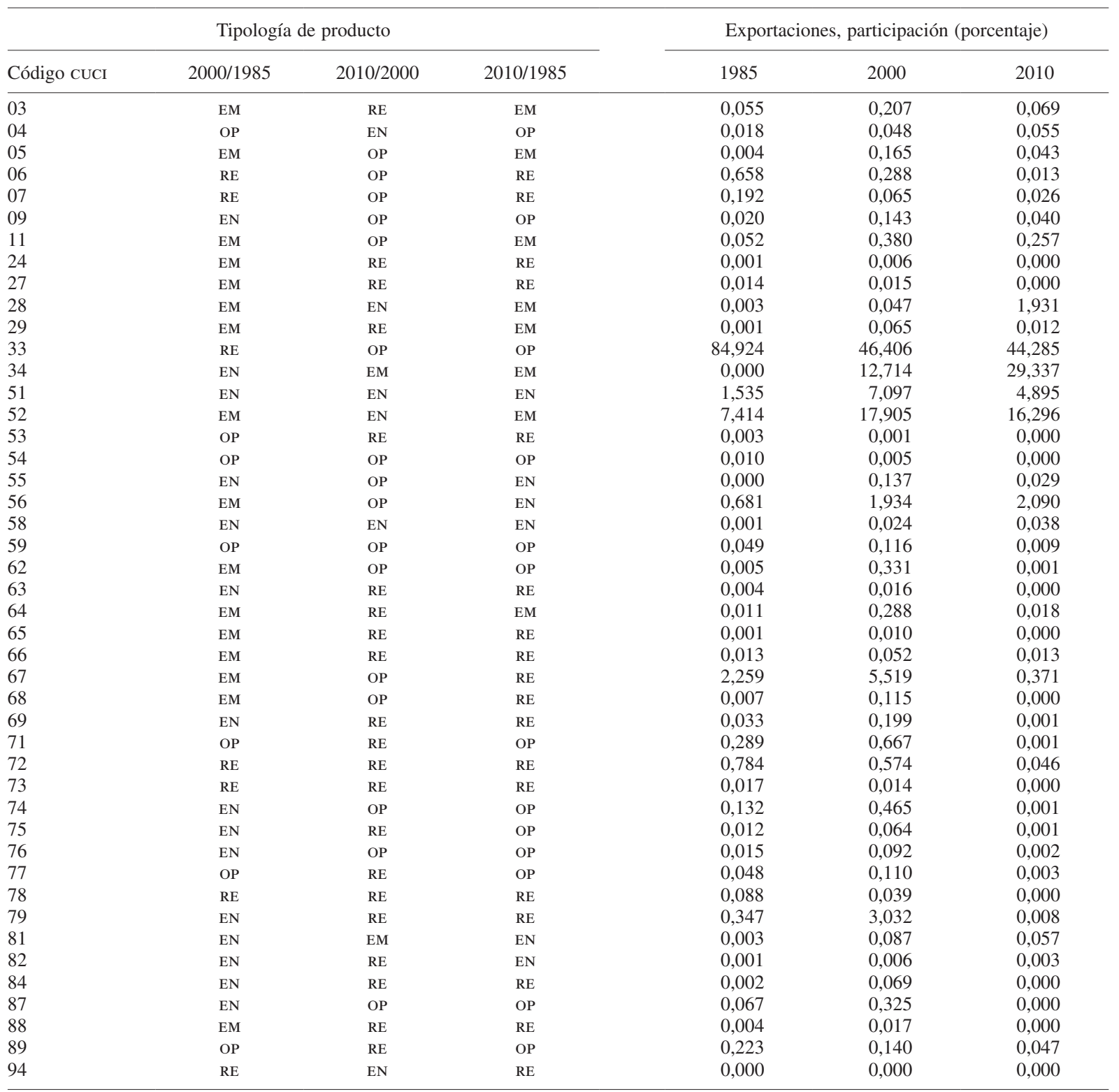

Fuente: Elaboración propia sobre la base de información de TradecAN.

Nota: EM: Estrellas menguantes; RE: Retiradas; EN: Estrellas nacientes; oP: Oportunidades perdidas. CUCI: Clasificación Uniforme para el Comercio Internacional. 
CUADRO A.2

Trinidad y Tabago: tipología de las exportaciones en el mercado mundial (1)

\begin{tabular}{|c|c|c|c|c|c|c|}
\hline \multicolumn{4}{|c|}{ Tipología } & \multicolumn{3}{|c|}{ Exportaciones, participación (porcentaje) } \\
\hline Código CUCI & $2000 / 1985$ & $2010 / 2000$ & $2010 / 1985$ & 1985 & 2000 & 2010 \\
\hline 00 & $\mathrm{RE}$ & $\mathrm{RE}$ & $\mathrm{RE}$ & 0,028 & 0,003 & 0,000 \\
\hline 01 & EM & OP & EM & 0,032 & 0,151 & 0,098 \\
\hline 02 & EM & $\mathrm{RE}$ & $\mathrm{RE}$ & 0,056 & 0,224 & 0,033 \\
\hline 03 & EN & $\mathrm{RE}$ & EM & 0,065 & 0,326 & 0,124 \\
\hline 04 & EM & OP & EM & 0,476 & 1,381 & 0,844 \\
\hline 05 & EM & $\mathrm{RE}$ & EM & 0,186 & 0,772 & 0,660 \\
\hline 06 & $\mathrm{RE}$ & $\mathrm{RE}$ & $\mathrm{RE}$ & 2,396 & 1,481 & 0,093 \\
\hline 07 & EM & OP & $\mathrm{RE}$ & 0,529 & 0,386 & 0,207 \\
\hline 08 & EM & OP & EM & 0,008 & 0,398 & 0,063 \\
\hline 09 & EN & OP & EN & 0,226 & 0,826 & 0,580 \\
\hline 11 & EN & $\mathrm{RE}$ & EM & 1,335 & 3,071 & 1,758 \\
\hline 12 & EM & EM & EM & 0,030 & 0,454 & 0,687 \\
\hline 22 & $\mathrm{RE}$ & OP & OP & 0,013 & 0,003 & 0,000 \\
\hline 23 & EM & OP & $\mathrm{RE}$ & 0,000 & 0,000 & 0,000 \\
\hline 24 & EM & EM & EM & 0,006 & 0,027 & 0,024 \\
\hline 25 & EM & $\mathrm{RE}$ & $\mathrm{RE}$ & 0,019 & 0,021 & 0,009 \\
\hline 26 & EM & $\mathrm{RE}$ & EM & 0,002 & 0,001 & 0,001 \\
\hline 27 & $\mathrm{RE}$ & EM & $\mathrm{RE}$ & 0,752 & 0,083 & 0,243 \\
\hline 28 & EM & EN & EN & 0,023 & 0,055 & 0,444 \\
\hline 29 & EM & $\mathrm{RE}$ & $\mathrm{RE}$ & 0,007 & 0,031 & 0,001 \\
\hline 32 & $\mathrm{RE}$ & OP & $\mathrm{RE}$ & 0,001 & 0,000 & 0,000 \\
\hline 33 & EM & OP & $\mathrm{RE}$ & 66,374 & 46,389 & 39,823 \\
\hline 34 & EM & EN & EM & 0,745 & 9,173 & 30,824 \\
\hline 41 & EM & OP & $\mathrm{RE}$ & 0,000 & 0,000 & 0,000 \\
\hline 42 & EM & OP & EN & 0,004 & 0,194 & 0,045 \\
\hline 43 & EM & OP & EM & 0,000 & 0,013 & 0,001 \\
\hline 51 & $\mathrm{EN}$ & OP & $\mathrm{EN}$ & 2,209 & 4,254 & 5,208 \\
\hline 52 & $\mathrm{RE}$ & EN & $\mathrm{RE}$ & 9,577 & 2,123 & 3,041 \\
\hline 53 & OP & $\mathrm{RE}$ & $\mathrm{RE}$ & 0,276 & 0,229 & 0,105 \\
\hline 54 & EN & OP & OP & 0,038 & 0,122 & 0,008 \\
\hline
\end{tabular}

Fuente: Elaboración propia sobre la base de información de TradecAN.

Nota: EM: Estrellas menguantes; RE: Retiradas; EN: Estrellas nacientes; oP: Oportunidades perdidas. CUCI: Clasificación Uniforme para el Comercio Internacional. 
CUADRO A.3

Trinidad y Tabago: tipología de las exportaciones en el mercado mundial (2)

\begin{tabular}{|c|c|c|c|c|c|c|}
\hline \multicolumn{4}{|c|}{ Tipología } & \multicolumn{3}{|c|}{ Exportaciones, participación (porcentaje) } \\
\hline Código CUCI & $2000 / 1985$ & $2010 / 2000$ & $2010 / 1985$ & 1985 & 2000 & 2010 \\
\hline 56 & $\mathrm{RE}$ & EN & $\mathrm{RE}$ & 4,474 & 1,048 & 1,874 \\
\hline 57 & $\mathrm{RE}$ & $\mathrm{RE}$ & $\mathrm{RE}$ & 0,003 & 0,002 & 0,000 \\
\hline 58 & EN & OP & EN & 0,020 & 0,345 & 0,188 \\
\hline 59 & EN & $\mathrm{OP}$ & $\mathrm{OP}$ & 0,149 & 0,258 & 0,150 \\
\hline 61 & $\mathrm{OP}$ & $\mathrm{RE}$ & $\mathrm{RE}$ & 0,002 & 0,000 & 0,000 \\
\hline 62 & OP & $\mathrm{OP}$ & $\mathrm{OP}$ & 0,020 & 0,016 & 0,003 \\
\hline 63 & EN & $\mathrm{RE}$ & EM & 0,024 & 0,451 & 0,063 \\
\hline 64 & EN & $\mathrm{RE}$ & EM & 0,284 & 2,300 & 1,025 \\
\hline 65 & EM & $\mathrm{RE}$ & $\mathrm{RE}$ & 0,226 & 0,460 & 0,022 \\
\hline 66 & EM & $\mathrm{RE}$ & $\mathrm{RE}$ & 0,442 & 1,482 & 0,421 \\
\hline 67 & EM & OP & EM & 3,947 & 6,598 & 8,756 \\
\hline 68 & $\mathrm{RE}$ & OP & OP & 0,042 & 0,043 & 0,031 \\
\hline 71 & OP & OP & $\mathrm{OP}$ & 0,337 & 0,100 & 0,001 \\
\hline 72 & EM & $\mathrm{RE}$ & $\mathrm{RE}$ & 0,167 & 0,544 & 0,053 \\
\hline 73 & $\mathrm{RE}$ & $\mathrm{RE}$ & $\mathrm{RE}$ & 0,011 & 0,011 & 0,000 \\
\hline 74 & EN & OP & OP & 0,203 & 0,931 & 0,046 \\
\hline 75 & OP & $\mathrm{RE}$ & $\mathrm{OP}$ & 0,028 & 0,035 & 0,000 \\
\hline 76 & OP & $\mathrm{OP}$ & OP & 0,313 & 0,179 & 0,000 \\
\hline 77 & OP & $\mathrm{RE}$ & $\mathrm{OP}$ & 0,205 & 0,400 & 0,369 \\
\hline 78 & EN & EM & OP & 0,119 & 0,185 & 0,025 \\
\hline 79 & EM & $\mathrm{OP}$ & OP & 1,295 & 7,877 & 0,275 \\
\hline 81 & EN & $\mathrm{RE}$ & $\mathrm{OP}$ & 0,013 & 0,079 & 0,016 \\
\hline 82 & EN & $\mathrm{RE}$ & EN & 0,038 & 0,352 & 0,141 \\
\hline 83 & EN & $\mathrm{RE}$ & $\mathrm{OP}$ & 0,006 & 0,011 & 0,002 \\
\hline 84 & EN & $\mathrm{RE}$ & $\mathrm{RE}$ & 0,165 & 0,444 & 0,072 \\
\hline 85 & $\mathrm{OP}$ & $\mathrm{RE}$ & $\mathrm{RE}$ & 0,015 & 0,016 & 0,000 \\
\hline 87 & EN & $\mathrm{OP}$ & $\mathrm{OP}$ & 0,095 & 0,250 & 0,001 \\
\hline 88 & OP & $\mathrm{RE}$ & $\mathrm{RE}$ & 0,016 & 0,011 & 0,000 \\
\hline 94 & $\mathrm{OP}$ & $\mathrm{RE}$ & $\mathrm{RE}$ & 0,001 & 0,000 & 0,000 \\
\hline 95 & EM & $\mathrm{RE}$ & $\mathrm{RE}$ & 0,000 & 0,000 & 0,000 \\
\hline
\end{tabular}

Fuente: Elaboración propia sobre la base de información de Tradecan.

Nota: EM: Estrellas menguantes; RE: Retiradas; EN: Estrellas nacientes; oP: Oportunidades perdidas. CUCI: Clasificación Uniforme para el Comercio Internacional. 
CUADRO A.4

\section{Descripción de códigos de productos (CUCl)}

\section{Código Descripción}

$00 \quad$ Animales vivos principalmente para comer

01 Carne y preparados de carne

02 Productos lácteos y huevos de aves

03 Pescado (no incluidos los mamíferos marinos), crustáceos, moluscos e invertebrados acuáticos y sus preparados

04 Cereales y preparados de cereales

05 Legumbres y frutas

06 Azúcares, preparados de azúcar y miel

07 Café, té, cacao, especias y sus preparados

08 Pienso para animales (excepto cereales sin moler)

09 Productos y preparados comestibles diversos

11 Bebidas

12 Tabaco y sus productos

22 Semillas y frutos oleaginosos

23 Caucho en bruto (incluso el caucho sintético y regenerado)

24 Corcho y madera

25 Pasta y desperdicios de papel

26 Fibras textiles (excepto las mechas (tops) y otras formas de lana peinada) y sus desperdicios (no manufacturadas en hilados, hilos o tejidos)

27 Abonos en bruto, excepto los del capítulo 56, y minerales en bruto (excepto carbón, petróleo y piedras preciosas)

28 Menas y desechos de metales

29 Productos animales y vegetales en bruto, n.e.p.

32 Hulla, coque y briquetas

33 Petróleo, productos derivados del petróleo y productos conexos

34 Gas natural y manufacturado

41 Aceites y grasas de origen animal

42 Aceites y grasas fijos de origen vegetal, en bruto, refinados o fraccionados

43 Aceites y grasas de origen animal o vegetal, elaborados; ceras de origen animal o vegetal; mezclas o preparados no comestibles de grasas o aceites de origen animal o vegetal, n.e.p.

51 Productos químicos orgánicos

52 Productos químicos inorgánicos

53 Materias tintóreas, curtientes y colorantes

54 Productos medicinales y farmacéuticos

55 Aceites esenciales y resinoides y productos de perfumería; preparados de tocador y para pulir y limpiar

56 Abonos, manufacturados

57 Plásticos en formas primarias

58 Plásticos en formas no primarias

59 Materias y productos químicos, n.e.p.

61 Cuero y manufacturas de cuero, n.e.p., y pieles finas curtidas

62 Manufacturas de caucho, n.e.p.

63 Manufacturas de corcho y de madera (excepto muebles)

64 Papel, cartón y artículos de pasta de papel, de papel o de cartón

65 Hilados, tejidos, artículos confeccionados de fibras textiles, n.e.p., y productos conexos

66 Manufacturas de minerales no metálicos, n.e.p.

67 Hierro y acero

68 Metales no ferrosos

69 Manufacturas de metales, n.e.p.

71 Maquinaria y equipos generadores de fuerza

72 Maquinarias especiales para determinadas industrias

73 Máquinas para trabajar metales 
Cuadro A.4 (conclusión)

\begin{tabular}{|ll} 
Código & Descripción \\
\hline 74 & Maquinaria y equipo industrial en general, n.e.p., y partes y piezas de máquinas, n.e.p. \\
\hline 75 & Máquinas de oficina y máquinas de procesamiento automático de datos \\
\hline 76 & Aparatos y equipo para telecomunicaciones y para grabación y reproducción de sonido \\
\hline 78 & $\begin{array}{l}\text { Maquinaria, aparatos y artefactos eléctricos, n.e.p., y sus partes y piezas eléctricas (incluso las contrapartes no eléctricas, n.e.p., } \\
\text { del equipo eléctrico de uso doméstico) }\end{array}$ \\
\hline 79 & Oehículos de carretera (incluso aerodeslizadores) \\
\hline 81 & $\begin{array}{l}\text { Edificios prefabricados; artefactos y accesorios sanitarios y para sistemas de conducción de aguas, calefacción y alumbrado, } \\
\text { n.e.p. }\end{array}$ \\
\hline 82 & Muebles y sus partes; camas, colchones, somieres, cojines y artículos rellenos similares \\
\hline 83 & Artículos de viajes, bolsos de mano y otros artículos análogos para contener objetos \\
\hline 85 & Prendas y accesorios de vestir \\
\hline 87 & Calzado \\
\hline 88 & Anstrumentos y aparatos profesionales, científicos y de control, n.e.p. \\
\hline 89 & Artículos manufacturados diversos, n.e.p. \\
\hline 93 & Operaciones y mercancías especiales no clasificadas según su naturaleza \\
\hline 94 & Animales vivos, animales de zoológico, perros, gatos \\
\hline 95 & Armas, de guerra y munición \\
\hline
\end{tabular}

Fuente: Elaboración propia sobre la base de información de Tradecan.

Nota: CUCI: Clasificación Uniforme para el Comercio Internacional; n.e.p.: no especificados en otra parte.

\section{Bibliografía}

Aguirre, Álvaro y César Calderón (2005), "Real exchange rate misalignments and economic performance", Documentos de Trabajo, $\mathrm{N}^{\circ} 315$, Santiago, Banco Central de Chile [en línea] www.bcentral.cl/eng/studies/working-papers/pdf/ dtbc315.pdf.

Balassa, Bela (1986), "Comparative advantage in manufactured goods: a reappraisal", The Review of Economics and Statistics, vol. $68, \mathrm{~N}^{\circ} 2$, Cambridge, Massachusetts, The MIT Press.

(1977), "'Revealed' comparative advantage revisited: an analysis of relative export shares of the industrial countries, 1953-1971", The Manchester School, vol. 45, № 4, Wiley.

(1965), "Trade liberalization and 'revealed' comparative advantage", The Manchester School, vol. 33, $\mathrm{N}^{\circ} 2$, Wiley.

Buitelaar, Rudolf (1997), "La posición de los países pequeños en el mercado de las importaciones de los Estados Unidos: efectos del TLC y la devaluación mexicana", serie Desarrollo Productivo, N 39 (LC/G.1948), Santiago, Comisión Económica para América Latina y el Caribe (CEPAL).

CEPAL (Comisión Económica para América Latina y el Caribe) (2013), Panorama fiscal de América Latina y el Caribe. Reformas tributarias y renovación del pacto fiscal (LC/L.3580), Santiago.

(2012), Cambio estructural para la igualdad. Una visión integral de desarrollo (LC/G.2524(SES.34/3)), Santiago.

Corden, Max y J. Peter Neary (1982), "Booming sector and deindustrialization in a small open economy", The Economic Journal, vol. 92, $\mathrm{N}^{\circ} 368$, Wiley.

Dussel, Enrique (2004), "La competitividad de la industria maquiladora de exportación en Honduras. Condiciones y retos ante el CAFTA" (LC/MEX/R.853), Ciudad de México [en línea] http://www.eclac.cl/cgi-bin/getProd.asp?xml=/publicaciones/ $\mathrm{xml} / 8 / 14258 / \mathrm{P} 14258 . x \mathrm{ml} \& \mathrm{xsl}=/ \mathrm{mexico} / \mathrm{tpl} / \mathrm{p} 9 \mathrm{f} . \mathrm{xs} 1 \&$ base=/ mexico/tpl/top-bottom.xsl.
(2001), "Un análisis de la competitividad de las exportaciones de prendas de vestir de Centroamérica utilizando los programas y la metodología CAN y MAGIC", serie Estudios y Perspectivas, $\mathrm{N}^{\circ} 1$ (LC/L.1520-P), Ciudad de México, Sede Subregional de la CEPAL en México.

Hernández, René A. e Indira Romero (2009), “Módulo para analizar el crecimiento del comercio internacional (MAGIC Plus). Manual para el usuario", serie Estudios y Perspectivas, $\mathrm{N}^{\circ} 107$ (LC/ MEX/L.898), Ciudad de México, Sede Subregional de la CEPAL en México.

Hernández, René A., Indira Romero y Martha Cordero (2006), “iSe erosiona la competitividad de los países del DR-CAFTA con el fin del acuerdo de textiles y vestuario?", serie Estudios y Perspectivas, $\mathrm{N}^{\circ} 50$ (LC/L.2545-P), Ciudad de México, Sede Subregional de la CEPAL en México.

Lafay, Gérard (1979), Dynamique de la spécialisation international, París, Economica.

Loayza, Norman y otros (2007), "Macroeconomic volatility and welfare in developing countries: an introduction", World Bank Economic Review, vol. 21, $\mathrm{N}^{\circ} 3$, Washington, D.C., Banco Mundial.

Martínez, Jorge M. y Enrique Cortés (2004), "Competitividad centroamericana", serie Estudios y Perspectivas, $\mathrm{N}^{\circ} 21$ (LC/L.2152-P), Ciudad de México, Sede Subregional de la CEPAL en México.

Mortimore, Michael, Rudolf Buitelaar y José Luis Bonifaz (2000), "México: un CANálisis de su competitividad internacional", serie Desarrollo Productivo, № 62 (LC/L.1268-P), Santiago, Comisión Económica para América Latina y el Caribe (CEPAL).

Stiglitz, Joseph (2012), "From resource curse to blessing", Project Syndicate [en línea] http://www.project-syndicate.org/ commentary/from-resource-curse-to-blessing-by-joseph-e --stiglitz. 